\title{
Corrosion Behavior of NiCrFe Alloy 600 in High Temperature, Hydrogenated Water
}

\author{
SE Ziemniak and ME Hanson
}

This report was prepared as an account of work sponsored by the United States Government. Neither the United States, nor the United States Department of Energy, nor any of their employees, nor any of their contractors, subcontractors, or their employees, makes any warranty, express or implied, or assumes any legal liability or responsibility for the accuracy, completeness or usefulness of any information, apparatus, product or process disclosed, or represents that its use would not infringe privately owned rights. 
Corrosion Behavior of NiCrFe Alloy 600 in High Temperature, Hydrogenated Water

Stephen E. Ziemniak

Michael Hanson

September 2004

Lockheed Martin Corporation

P. O. Box 1072

Schenectady, New York, 12301-1072 


\begin{abstract}
The corrosion behavior of Alloy 600 (UNS N06600) is investigated in hydrogenated water at $260^{\circ} \mathrm{C}$. The corrosion kinetics are observed to be parabolic, the parabolic rate constant being determined by chemical descaling to be $0.055 \mathrm{mg} \mathrm{dm}^{-2} \mathrm{hr}^{-1 / 2}$. A combination of scanning and transmission electron microscopy, supplemented by energy dispersive X-ray spectroscopy and grazing incidence X-ray diffraction, are used to identify the oxide phases present (i.e., spinel) and to characterize their morphology and thickness. Two oxide layers are identified: an outer, ferrite-rich layer and an inner, chromite-rich layer. X-ray photoelectron spectroscopy with argon ion milling and target factor analysis is applied to determine spinel stoichiometry; the inner layer is $\left(\mathrm{Ni}_{0.7} \mathrm{Fe}_{0.3}\right)\left(\mathrm{Fe}_{0.3} \mathrm{Cr}_{0.7}\right)_{2} \mathrm{O}_{4}$, while the outer layer is $\left(\mathrm{Ni}_{0.9} \mathrm{Fe}_{0.1}\right)\left(\mathrm{Fe}_{0.85} \mathrm{Cr}_{0.15}\right)_{2} \mathrm{O}_{4}$. The distribution of trivalent iron and chromium cations in the inner and outer oxide layers is essentially the same as that found previously in stainless steel corrosion oxides, thus confirming their invariant nature as solvi in the immiscible spinel binary $\mathrm{Fe}_{3} \mathrm{O}_{4}-\mathrm{FeCr}_{2} \mathrm{O}_{4}$ (or $\mathrm{NiFe}_{2} \mathrm{O}_{4}$ $\mathrm{NiCr}_{2} \mathrm{O}_{4}$ ). Although oxidation occurred non-selectively, excess quantities of nickel(II) oxide were not found. Instead, the excess nickel was accounted for as recrystallized nickel metal in the inner layer, as additional nickel ferrite in the outer layer, formed by pickup of iron ions from the aqueous phase, and by selective release to the aqueous phase.
\end{abstract}

KEYWORDS: (A) superalloys; (B) AES, XPS; (C) passive films, non-selective oxidation 


\section{$\underline{\text { INTRODUCTION }}$}

Recent advances in ability to characterize indigenous oxide layers that form on corroding $\mathrm{NiCrFe}$ alloy substrates have revealed a synergism between alloy corrosion and chemical aspects of the metal oxide corrosion layer. In these cases, spinel oxides $\left(\mathrm{AB}_{2} \mathrm{O}_{4}\right)$ are formed and an understanding of the manner in which their metal cations distribute among two lattice sites in the oxide - octahedral and tetrahedral - is important. For example, the B cations are Fe(III) and $\mathrm{Cr}(\mathrm{III})$, and the $\mathrm{AFe}_{2} \mathrm{O}_{4}$ oxides (ferrites) are inverse spinels while the $\mathrm{ACr}_{2} \mathrm{O}_{4}$ oxides (chromites) are normal spinels. One consequence of this distribution is that a single phase, solid solution is not stable over an unlimited range of composition and solid phase immiscibility occurs: one phase is chromite-rich (inner layer) and one phase is ferrite-rich (outer layer). Investigations of an austenitic iron-base $\mathrm{CrNi}$ alloy (304 stainless steel) demonstrated the coincidence between compositions of the inner and outer corrosion oxide layers [1] and solvus phases in the $\mathrm{Fe}_{3} \mathrm{O}_{4^{-}}$ $\mathrm{FeCr}_{2} \mathrm{O}_{4}$ binary [2].

Follow-on work with a nickel-base CrMo alloy (Alloy 625) found that non-selective oxidation created inner and outer layer spinel oxide corrosion films representative of solvus phases in the $\mathrm{NiFe}_{2} \mathrm{O}_{4}-\mathrm{NiCr}_{2} \mathrm{O}_{4}$ binary [3]. The higher nickel levels, however, led to two additional chemical phenomena: (1) recrystallization of excess $\mathrm{Ni}(\mathrm{II})$ ions in the inner layer as metallic nickel and (2) pickup of non-indigenous iron ions from the aqueous phase to create additional amounts of hydrothermally-grown nickel ferrite from outwardly-diffusing Ni(II) ions in the inner layer. Both reactions are a consequence of the inability to form a separate phase of nickel(II) oxide in the presence of dissolved hydrogen. 
To complement an on-going immiscibility study of the $\mathrm{NiFe}_{2} \mathrm{O}_{4}-\mathrm{NiCr}_{2} \mathrm{O}_{4}$ binary in our laboratory, a corrosion study of a second nickel-base $\mathrm{CrFe}$ alloy was undertaken. This test exposed NiCrFe Alloy 600, a nickel-base $16 \mathrm{Cr} 9 \mathrm{Fe}$ alloy, to mildly alkaline, hydrogenated water at $260^{\circ} \mathrm{C}$. The unique composition of Alloy 600 allowed a $\mathrm{NiCrFe}$ alloy to be studied that had nearly the same $\mathrm{Cr} / \mathrm{Fe}$ ratio as the chromite-rich solvus phase in the $\mathrm{Ni}\left(\mathrm{Fe}_{1-\mathrm{x}} \mathrm{Cr}_{\mathrm{x}}\right)_{2} \mathrm{O}_{4}$ spinel binary. Two types of corrosion specimens were tested: (1) 4" coupons were used to monitor corrosion behavior via gravimetric analysis, and (2) highly polished 3/4" specimens were used to determine elemental/oxidation state distribution within the corrosion layer(s) by subjecting them to detailed in-situ characterizations by scanning electron microscopy (SEM), transmission electron microscopy (TEM), grazing incidence X-ray diffraction (GIXRD) and X-ray photoelectron spectroscopy (XPS)/ion milling.

\section{EXPERIMENTAL}

Corrosion specimens of NiCrFe Alloy 600 (UNS N06600) were exposed in a flowing autoclave facility $\left(10 \mathrm{~cm}^{3} / \mathrm{min}\right.$ ) comprised of a one liter, type 347 stainless steel (UNS S34700) vessel, and fed from stainless steel tanks containing deionized, hydrogen-sparged water whose $\mathrm{pH}$ was maintained slightly alkaline $\left(\mathrm{pH}\left(@ 260^{\circ} \mathrm{C}\right)=6.70\right)$. The dissolved hydrogen concentration was $45 \mathrm{scm}^{3}$ (@STP) $\mathrm{kg}^{-1}$. Test shutdowns, along with specimen removals and insertions, occurred intermittently, so that exposure times ranged between 1000 and 10,000 hours. Standard corrosion coupons ( 4 " x 3/4" x .032") were machined from Alloy 600. Smaller specimens for corrosion film analysis (5/8" x 3/4" x 1/16") were also machined from the same stock; one side of each being polished to a mirror finish ( $\sim 6 \mu \mathrm{in}$. AA) using diamond grit paste to facilitate instrumental resolution. 


\section{ANALYTICAL PROCEDURES}

\section{$\underline{\text { Gravimetric Analysis }}$}

Triplicate corrosion coupons were descaled using a two-step alkaline permanganate-ammonium citrate (AP/AC) process: (1) $1 \% \mathrm{KMnO}_{4}$ and $5 \% \mathrm{NaOH}$ for 30 min at $90^{\circ} \mathrm{C}$, followed by wiping and (2) $5 \%\left(\mathrm{NH}_{4}\right)_{2}$ citrate for $30 \mathrm{~min}$ at $90^{\circ} \mathrm{C}$. This method involves multiple applications and a reverse extrapolation to correct for base metal losses during corrosion oxide removal, per ASTM procedure G1-67. A minimum of three and a maximum of four process applications were performed. All weights were measured with an accuracy of $\pm 0.02 \mathrm{mg}$ using a calibrated, 5place balance.

\section{Transmission Electron Microscopy (TEM)}

This procedure was employed to obtain microstructural details, including inner layer composition and morphology, at high magnifications $(\sim 100,000 \mathrm{X})$. The analyses were performed using a Philips CM300 analytical electron microscope.

Representative sections were prepared by cutting $3 \mathrm{~mm}$ by $10 \mathrm{~mm}$ strips from the corrosion specimens and mechanically thinning to a thickness of $100 \mu \mathrm{m}$ from the substrate side. After protecting the oxide with epoxy, the ground surface was electropolished to the desired thickness using a solution of $20 \%$ perchloric acid in methanol. The epoxy coating was subsequently removed prior to AEM analysis. 
Since the resulting mount was extremely thin, the entire oxide layer could be analyzed at the same time. Additional, quantitative characterizations of the phases isolated by TEM were obtained using a combination of electron diffraction and X-ray spectroscopy (EDX) of $5 \mathrm{~nm}$ sized regions.

\section{Grazing Incidence X-Ray Diffraction (GIXRD)}

Approximate thicknesses and unit cell dimensions of phases in the corrosion oxide layer were determined by GIXRD. This analysis was performed at Brookhaven National Laboratory using Beamline X3B1 of the National Synchrotron Light Source. This station is equipped with parallel beam optics and was operated at an incident X-ray wavelength of $1.14965 \AA$ to reduce sample absorption and minimize the fluorescence background. The wavelength as well as the detector zero position, was calibrated using a NIST $\mathrm{Al}_{2} \mathrm{O}_{3}$ standard. Counting time varied between one and two sec, and the step size was always $0.02^{\circ}$.

For X-rays incident on a solid from air, a critical angle $\left(\phi_{c}, \mathrm{rad}\right)$ is known to exist [4], below which total external reflection occurs:

$$
\phi_{\mathrm{c}}=(2 \delta)^{1 / 2}
$$

where

$$
\delta=\mathrm{N}_{\mathrm{O}}\left(\mathrm{e}^{2} / 2 \mathrm{Bmc}^{2}\right)(\mathrm{ZDA}) \lambda^{2}=2.797 \times 10^{6}(\mathrm{ZD} A) \lambda^{2}
$$

and $\mathrm{Z}$ is the average atomic number, $\mathrm{A}$ is the average atomic mass, Dis the mass density $\left(\mathrm{g} / \mathrm{cm}^{3}\right)$ and $\lambda$ is the X-ray wavelength ( $\AA$ ). The actual relationship between $\phi$ and penetration depth (D), however, is non-linear and D increases rapidly with $\phi$ in the vicinity of $\phi_{c}$ as the source of diffracted X-rays changes from reflection to absorption [4, 5]. 


$$
D=\left(\frac{\lambda \sqrt{2}}{4 \pi}\right)\left[\sqrt{\left(\phi^{2}-\phi_{c}^{2}\right)^{2}+4\left(\delta_{i}\right)^{2}}+\phi_{c}^{2}-\phi^{2}\right]^{-1 / 2}
$$

where $\delta_{i}=\lambda \mu /(4 \mathrm{~B})$ and $\mu$ is the linear absorption coefficient.

Application of the grazing incidence formulas using Z, A and Dvalues for typical spinel oxides (i.e., $\mathrm{NiCr}_{2} \mathrm{O}_{4}, \mathrm{NiFe}_{2} \mathrm{O}_{4}$ and $\mathrm{FeCr}_{2} \mathrm{O}_{4}$ ) yields an expected critical incidence angle $\phi_{\mathrm{c}}=0.25^{\circ}$. The corresponding penetration depth at $\phi_{\mathrm{c}}$ is given by

$$
D_{c}=\left(\frac{\lambda}{4 \pi \mu}\right)^{1 / 2}
$$

Since $\mu=442.9 \mathrm{~cm}^{-1}\left(\mathrm{FeCr}_{2} \mathrm{O}_{4}\right)$ and $\mu=521.1 \mathrm{~cm}^{-1}\left(\mathrm{NiFe}_{2} \mathrm{O}_{4}\right)$ are calculated via application of the Bragg-Pierce Law [6], estimated $D_{c}$ values are around 13.0-14.5 nm. An increase in $\phi$ from $0.2^{\circ}$ to $0.3^{\circ}$ increases the 'sampling' depth from about 4 to $770 \mathrm{~nm}$. Therefore, rough estimates of oxide thickness could be obtained from analyses at increasing angles of grazing incidence near the critical angle based on: (1) increases in intensity of the major corrosion oxide peak or (2) emergence of the substrate peak. An independent estimate of oxide grain size was also possible by means of the Scherrer equation which relates XRD peak broadening to crystal size.

\section{X-Ray Photoelectron Spectroscopy (XPS)}

The composition of each polished sample was investigated as a function of depth by successively removing surface material by argon ion bombardment and analyzing the freshly uncovered surface by XPS. This analysis was performed using a Physical Electronics Model 5601 Microfocus ESCA (Electron Spectroscopy for Chemical Analysis) system. The spectrometer 
employed a monochromated aluminum X-ray source $(\mathrm{E}=1486.6 \mathrm{eV})$. Argon ion sputtering was performed with a differentially pumped ion gun operated at a beam voltage of $4 \mathrm{keV}$ with current densities in the range 32 to $40: \mathrm{A} / \mathrm{cm}^{2}$ using a $3 \times 3 \mathrm{~mm}$ raster. The ion beam was oriented approximately $60^{\circ}$ from the sample normal. To minimize shadowing and sputter-induced microfeature formations that degrade depth resolution, the sample was rotated at $1 \mathrm{rpm}$ during sputtering. XPS analyses were taken from a circular area $800 \mu \mathrm{m}$ diameter in the center of the 3 $\mathrm{mm}$ diameter sputter crater. Sputter time was converted to sputter depth by multiplying by an experimentally derived sputter rate. This was determined by conducting periodic depth profiling experiments on a silicon dioxide $\left(\mathrm{SiO}_{2}\right)$ sputter standard whose thickness was independently confirmed by profilometry. The $\mathrm{SiO}_{2}$ sputter rate was then converted to a $\mathrm{Ta}_{2} \mathrm{O}_{5}$ sputter rate using a multiplication factor of 1/0.85 (=1.176) since most transition metal oxides sputter at rates within $20 \%$ of the rate for $\mathrm{Ta}_{2} \mathrm{O}_{5}$.

Surface atomic compositions at each depth were derived by applying MultiPack $^{\mathrm{TM}}$, a software package developed by Physical Electronics for interpreting XPS data acquired on their instruments. This software facilitated data analysis by means of two pre-processing steps: (1) the Savitzky-Golay [7] smoothing algorithm, based on a 7-point running average, suitably modified for end points, was applied to reduce spectral noise, and (2) a Shirley [8], integrated background correction was obtained by successive iteration to minimize interference caused by the inelastic scattering of low energy electrons. Integration of the pre-processed data in each element region was then performed to obtain peak areas, which when multiplied by sensitivity factors, provided surface atom densities. The results were then normalized to obtain units of surface atom percent. 
Sensitivity factors were obtained by calibration versus a copper standard and adjusted internally by MultiPack. This methodology allowed the software to account for specific hardware characteristics, viz., energy-dependent transmission characteristics of the specific analyzers and the angle between $\mathrm{X}$-ray source and analyzer.

A change in oxidation state of an element is known to shift energies of its core electrons sufficiently so that it also becomes possible to extract information on oxidation state by suitable spectral deconvolution of XPS data. Although chemical state identification is a distinct advantage of XPS, data interpretation can be difficult when XPS is used in conjunction with ion beam sputtering in depth profiling experiments. Ion beams are known to reduce some oxides to suboxides or even to metals [9-11], so an overly simplistic interpretation of the chemical shift of an XPS spectrum in a depth profiling experiment may lead to incorrect conclusions. To allow for this effect, a constrained least-squares analytical technique, known as target factor analysis (TFA) [12], was used to deconvolute the pre-processed XPS data.

After selecting a given energy region for chemical state speciation, i.e., the chromium $2 p$ region (570-590 eV), the principal component analysis (PCA) routine is invoked to run mathematical tests on the data and determine the number of 'principal' components that may be present. The PCA is performed on all spectra of a given sample taken at different sputter depths. Depending on the number of principal components identified, a set of synthetic spectra ('eigen spectra') is generated from the PCA and the pre-processed data. In the case of chromium, for example, two eigen spectra were identified: one corresponding to $\mathrm{Cr}(0)$ and one to $\mathrm{Cr}(\mathrm{III})$. The target factor analysis (TFA) routine is then called to deconvolute each spectrum, by linear least squares 
regression, into a linear combination of the eigen spectra ('target' spectra). These linear fractions of the eigen/target spectra at each depth provide profiles of the indicated speciation in chemical state.

Some flexibility is permitted in the Phi-MultiPak software to determine the number of eigen spectra, thus the number of chemical states, that are contained within the raw data. Subjective tests are applied to the target solutions by the operator to determine whether a given target component is significant (real signal) or insignificant (random noise). Experience with TFA has shown that optimal results are obtained when the surface has been sputtered to a depth sufficient to remove all oxygen. This technique ensures that an eigen spectrum truly representative of the metallic state will be obtained.

Physical interpretation of a given eigen spectrum, which is left to the analyst, may also lead to several areas of subjectivity. For example, a sputter-damaged compound may display an eigen spectrum unique from the unsputtered compound. This happens to be the case in this work, where two $\mathrm{Ni}(2 \mathrm{p})$ eigen spectra have been associated with the same $\mathrm{Ni}(\mathrm{II})$ compound; one component sputter damaged and the other not. These components were added together to represent the total $\mathrm{Ni}(\mathrm{II})$ concentration. The case of iron is even more complex because two nonzero oxidation states exist: Fe(II) and Fe(III), and both may become sputter-damaged. This complication was addressed by assuming that the corrosion oxide existed only as spinel compounds: $\mathrm{AB}_{2} \mathrm{O}_{4}$. Here $\mathrm{A}$ refers to a divalent metal ion: $\mathrm{Ni}(\mathrm{II})$ or $\mathrm{Fe}(\mathrm{II})$; and $\mathrm{B}$ is a trivalent metal ion: $\mathrm{Cr}(\mathrm{III})$ or Fe(III). This assumption is justified because the GIXRD results established the sole presence of spinel and alloy substrate. No XRD lines remained unidentified. Due to 
overlap of the Ni Auger (LMM) lines in the Fe $2 p$ region, the Fe $3 p$ region was selected for deconvolution by TFA.

An internal consistency check on the resulting speciation in oxidation states was obtained by summing the (inferred) oxygen bonded to the (measured) oxidized metal species and comparing to the measured $\mathrm{O}(1 \mathrm{~s})$ signal. Because oxygen is less massive than the transition metal elements, it tends to sputter preferentially, so that the $\mathrm{O}(1 \mathrm{~s})$ signal was always greater (by a small amount) than the oxygen accounted for by summing the oxidized metal species.

The above caveats are mentioned because the combined XPS/ion milling/TFA methodology is rather recent and has not yet been widely applied to corrosion analyses. However, by applying the above consistency checks at various stages of the analysis, it became possible to provide accurate chemical state speciations versus sputter depth. The resulting profiles were then integrated versus depth to provide an independent, in-situ method for quantifying the amount, and distribution, of oxidized metals in the corrosion oxide layer.

\section{$\underline{\text { RESULTS }}$}

\section{A. Gravimetric Analysis}

Specimen descale weight losses due to corrosion (corrected for base metal attack during scale removal) are summarized in Table I. These data were converted to surface densities by dividing by the surface area per specimen $\left(0.4078 \mathrm{dm}^{2}\right)$. When correlated to an expected parabolic rate expression:

$$
w, m g d m^{-2}=\left(k_{p}\right) t^{1 / 2}
$$


the parabolic rate constant $\left(\mathrm{k}_{\mathrm{p}}\right)$ is found to be $0.055 \pm 0.009 \mathrm{mg} \mathrm{dm}^{-2} \mathrm{hr}^{-1 / 2}$.

Table I also shows that the corrosion specimens lost weight during the first half of the test, while they gained weight during the second half of the test. Weight losses were expected, and are indicative of release/dissolution of the corrosion oxide to the aqueous phase, while an increase indicates retention (or possibly pickup of metal ions from the water). It is noteworthy that some weight increases were in excess of those accountable by the pickup of oxygen required to form corrosion oxide spinels - $\mathrm{M}(\mathrm{Fe}, \mathrm{Cr})_{2} \mathrm{O}_{4}$. For example, in the case of zero release

$$
\text { final wgt. }=\text { pretest wgt. }+ \text { oxygen in cor. oxide }
$$

If it is assumed that zero release is represented by the complete retention of recrystallized nickel and all spinels, then a material balance reveals that 4.3 moles of $\mathrm{Ni}$ will be formed for each mole of spinel created, i.e., corrosion layer is $47.6 \mathrm{wgt}$ \% spinel. Since the overall spinel composition, $\mathrm{Ni}\left(\mathrm{Fe}_{0.34} \mathrm{Cr}_{0.66}\right)_{2} \mathrm{O}_{4}$, has an average oxygen content 27.9 wgt. \%, the zero release case is written

$$
\text { zero release }=\text { wgt. gain due to oxygen in corr. oxide }=\frac{(0.476)(0.279)}{(1-0.279)} \times(\text { metals oxidized })
$$

By subtracting the specimen weight increase associated with zero release from the measured specimen weight increases, an estimate of (iron and additional oxygen) pickup from the test water was obtained, see final column of Table I. The amounts of pickup determined in this manner are necessarily underestimates because they actually represent the difference between pickup and release (and release estimates remain to be quantified).

The above result, however, is believed to represent the creation of a nickel ferrite-rich solvus phase to equilibrate with the nickel chromite-rich inner layer solvus phase and excess $\mathrm{Ni}$ (II) ions 
created during (non-selective) oxidation. Since $\mathrm{NiO}$ is not stable in a chemically-reducing environment, two routes are possible to relieve the excess $\mathrm{Ni}(\mathrm{II})$ ions: (1) recrystallization to metallic nickel and (2) stabilization as nickel ferrite by pickup of soluble iron ions from the aqueous phase. The balance between the two will be addressed upon closure of the material balances for oxidized chromium and iron.

\section{B. SEM/EDX}

All test specimens took on a dull, gray/black appearance upon exposure to the aqueous medium. Surfaces of the corroded Alloy 600 specimens, as recorded by high magnification SEM photographs, are shown in Fig. 1. Two crystal morphologies are observed: polyhedral and hexagonal platelet. Both are well-formed: the polyhedra range in size from $<100 \mathrm{~nm}$ (at 1000 hr) up to $1.5 \mathrm{Fm}$ (at $10,000 \mathrm{hr}$ ), while the platelet dimensions are $\sim 300 \mathrm{~nm}$ diam. by $20 \mathrm{~nm}$ thickness. The sequence of Fig. 1 (a) - (d) indicates that outer layer oxide growth with time occurred via increases in size and number density of the polyhedral crystals. Note that Figs. (a) and (b) are recorded at 50\% higher magnification than (c) and (d). Higher magnification SEM photos of the 1000 and $8000 \mathrm{hr}$ specimens, shown in Fig. 2, indicate that the platelet forms tended to grow into polyhedra.

In situ measurements of oxide crystal composition by EDX proved inconclusive, due to the small crystal size and penetrating nature of the probe. To eliminate substrate interference, the outer layer crystals were removed using replicating tape prior to performing EDX. Assuming a single phase spinel to be present resulted in an average composition of $\left(\mathrm{Ni}_{0.8} \mathrm{Fe}_{0.2}\right)\left(\mathrm{Fe}_{0.9} \mathrm{Cr}_{0.1}\right)_{2} \mathrm{O}_{4}$ for oxide crystals removed from two $8000 \mathrm{hr}$ specimens, see Table II. 


\section{C. $\underline{\text { TEM/AEM }}$}

One 10,000 hr specimen (I67) was prepared for examination by transmission electron microscopy. Planar views through the corrosion oxide surface layer, as captured in bright field images at 100,000X, are provided in Fig. 3. The corrosion oxide is seen to be polycrystalline in nature, having grain sizes in the range $10 \mathrm{~nm}$ to $0.3 \mu \mathrm{m}$. The larger crystallites appear as a blocky, faceted phase exhibiting dark contrast; the smaller crystallites are extremely fine grained, on the order of 50-100 $\mathrm{nm}$. It is probable that the larger crystallites correspond to the SEM surface crystals shown previously in Fig. 1. Electron diffraction performed on the oxide film and shown in the inset to Fig. 3 indicates the presence of a spinel oxide structure having a lattice parameter of approximately $8.4 \AA$. This result is consistent with the presence of both $\mathrm{MFe}_{2} \mathrm{O}_{4}$ and $\mathrm{MCr}_{2} \mathrm{O}_{4}$ oxides; no diffraction lines for $\mathrm{Cr}_{2} \mathrm{O}_{3}$ and $\mathrm{NiO}$ were found.

Supplemental EDX microanalyses of the two crystal populations indicate differences in oxide composition between the large and small crystals, see Table II. Spectra for the larger crystals indicate a ferrite-rich composition: $(\mathrm{Ni}, \mathrm{Fe})\left(\mathrm{Fe}_{2-\mathrm{x}} \mathrm{Cr}_{\mathrm{x}}\right) \mathrm{O}_{4}$, where $\mathrm{x}=0.2$; while the smaller crystals are chromite-rich: $(\mathrm{Ni}, \mathrm{Fe})\left(\mathrm{Fe}_{2-\mathrm{x}} \mathrm{Cr}_{\mathrm{x}}\right) \mathrm{O}_{4}$, where $\mathrm{x}=1.2$. In all cases nickel(II) ions constitute between 80 and $90 \%$ of the divalent metal ions in the spinel lattice. These results are consistent with the expected compositions of the respective outer and inner layers of the corrosion film.

\section{Grazing Incidence X-Ray Diffraction}

The GIXRD pattern for a 10,000 hr corrosion specimen (AX05) is recorded at a grazing incidence angle $\phi=0.5^{\circ}$ in Fig. 4a. All measured peaks are accounted for by the presence of two 
crystalline solids: an oxide spinel $\left(\mathrm{AB}_{2} \mathrm{O}_{4}\right)$ and a metallic nickel phase representative of unoxidized Alloy 600 base metal, see superimposed lines from JCPDS file cards [13]. Although the peaks for the alloy substrate were relatively broad, they remained symmetric, so that evidence for a recrystallized nickel phase was lacking. Under the present conditions, positions of the [111] peak for Alloy $600\left(a_{0}=3.561 \mathrm{D}\right)$ and recrystallized nickel $\left(a_{0}=3.524 \mathrm{D}\right)$ differ by about $0.25^{\circ}$, which should be observable.

Rough estimates of the oxide layer thickness were obtained by: (1) monitoring the emergence of the Ni[111] peak for unoxidized Alloy 600 substrate at increasing angles of grazing incidence and (2) relating spinel peak width to oxide grain size. Fig. $4 \mathrm{~b}$ shows that the [111] peak for Alloy 600 broke through at $\phi$ between 0.2 and $0.3^{\circ}$. Applying the expected X-ray penetration depth formula provides estimated oxide thicknesses around 14-35 nm.

An upper limit to the grain size of the spinel layer crystals was obtained from peak broadening estimates by applying the Scherrer equation [14] using full width at half maximum (FWHM) of the [311] peak:

$$
\text { size } \leq \frac{0.94 \lambda}{\mathrm{FWHM} \cdot \cos \theta}
$$

where $8=1.15 \mathrm{D}$ and $\theta=13^{\circ}$. Based on FWHM values measured at $\mathrm{N}=0.5^{\circ}$, the calculated grain sizes are: $42 \mathrm{~nm}\left(\mathrm{I} 45,0.15^{\circ}\right)$ and $63 \mathrm{~nm}\left(\mathrm{I} 41,0.10^{\circ}\right)$. The above may underestimate size because instrumental contribution is neglected. These results indicate that the (outer) oxide layer is one grain deep, consistent with partial coverage by Fm-size crystals. 
On the other hand, the XRD peaks of the Alloy 600 substrate were also broadened considerably. Such behavior is inconsistent with the known, coarse-grained microstructure of Alloy 600 . However, unlike the spinel lines, whose product FWHM@os $\theta$ was constant, the lines of the substrate exhibited FWHM values that increased with $\tan \theta$. This behavior is characteristic of a cold-worked surface. Based on constancy of the ratio between FWHM and $\tan \theta[6]$, it is estimated that microstrain was present in the alloy surface at levels around $0.4 \%$. This result was verified by obtaining a GIXRD pattern at a high angle $\left(\mathrm{N}=16^{\circ}\right)$ to increase penetration far into the bulk alloy. FWHM of the Ni [111] substrate peak decreased from $0.24^{\circ}$ to $0.09^{\circ}$; the lattice parameter remaining unchanged at $a_{0}=3.561 \pm 0.001 \mathrm{D}$. Similar results were obtained from analysis of an as-polished, unexposed specimen; see Fig. 5. Thus, substrate peak broadening is concluded to be a surface effect caused by the cold-working (i.e., machining/polishing) operations.

In order to obtain accurate unit cell dimension estimates for the spinel oxide phase, peak locations needed to be known with a high degree of confidence. Accurate peak positions were obtained by refining the raw data in two stages: (1) applying a prepositioning procedure, in which observed peak positions ( $\left.2 \theta_{\mathrm{obs}}\right)$ and FWHM were determined by fitting the Pearson VII function to each peak profile using a PC-based program SHADOW, followed by (2) corrections for the index of refraction.

Since the index of refraction of X-rays in the spinel oxide phase is slightly less than unity, all diffraction peaks were shifted to slightly higher angles than those calculated from Bragg's law. In conventional X-ray diffractometry the shift is usually neglected. However, for small 
incidence angles the Bragg angle shift due to refraction is much higher and must be taken into account in determining accurate lattice spacings. For $\phi<0.01 \mathrm{rad}$, Lim et al. [15] provide the shift in $2 \theta$ as

$$
\begin{aligned}
2 \theta=2 \theta_{\text {obs }}-2 \theta_{\text {cor }} \\
\\
\approx \frac{2 \delta}{\sin \left(2 \theta_{c o r}\right)}+\frac{\delta}{\phi}
\end{aligned}
$$

where ) $2 \theta$ and $\phi$ are in radians. The results of these calculations for $\phi=0.5^{\circ}$ are given in Table III. Unit cell parameters were finally determined from the corrected peak positions by leastsquares refinement, see Table III.

The relatively sharp lines of the spinel XRD pattern are consistent with the larger, outer layer crystals observed by SEM in Fig. 1, rather than the smaller, inner layer crystals. Per Table II, the outer layer crystals are ferrite-based and contain significant amounts of nickel(II). Invoking a linear decrease in lattice parameter between $\mathrm{Fe}_{3} \mathrm{O}_{4}\left(\mathrm{a}_{0}=8.396 \mathrm{D}\right.$, PDF 19-0629) and $\mathrm{NiFe}_{2} \mathrm{O}_{4}\left(\mathrm{a}_{0}\right.$ $=8.339 \mathrm{D}, \mathrm{PDF} 10-0325)$ [16], the measured lattice parameter $(8.351 \mathrm{D})$ provides an approximate stoichiometry for these crystals as $\left(\mathrm{Ni}_{0.8} \mathrm{Fe}_{0.2}\right) \mathrm{Fe}_{2} \mathrm{O}_{4}$, in good agreement with that inferred from the SEM/EDX analysis.

\section{E. $\underline{X P S / T F A}$}

Typical elemental composition versus depth profiles are shown in Figs. 6 and 7 for specimens having exposure times of 5000 and 10,000 hr, respectively. As expected, the major elements detected were oxygen, nickel, chromium and iron. Significant levels of carbon were also found on the surfaces of all specimens. Because the initial ion milling operation reduced the carbon 
signals to approximately that of the base alloy (i.e., $\sim 0.1 \%$ ), the carbon was concluded to be present as an adsorbed layer of hydrocarbon contamination, and was neglected when performing further analyses. This phenomenon has been reported previously [17], and is believed to be endemic to the surface.

The presence of outer layer corrosion oxides, i.e., the polyhedral crystals observed, growing on the specimen surfaces in Fig. 1, tended to manifest themselves by causing elongated 'tails' in the oxygen profiles, see Fig. 6 . Therefore, estimates of oxide thickness were obtained from the inflection point in each oxygen profile: a maximum in the first derivative represents the depth at which ion milling of the oxide layer exposed metal substrate at the most rapid rate. These results are summarized in Table IV. For consistency with the measured corrosion kinetics, increases in oxide thickness were correlated with a parabolic growth rate expression:

$$
\mathrm{O}(1 \mathrm{~s})=\mathrm{k}_{\mathrm{po}}(\mathrm{t})^{1 / 2}
$$

By least-squares analysis, it was found that $\mathrm{k}_{\mathrm{po}}=5.10 \pm 1.00 \mathrm{D} \mathrm{hr}^{-1 / 2}$, the estimated oxide thickness at 10,000 $\mathrm{hr}(51 \pm 10 \mathrm{~nm})$ agreeing with the coarse estimate obtained by GIXRD ( 63 $\mathrm{nm})$.

Converting to weight of metal oxide, assuming an oxide density $\sim 5.2 \mathrm{~g} \mathrm{~cm}^{-3}$, gives $\mathrm{k}_{\mathrm{po}}=0.026$ $\mathrm{mg}$ (spinel) $\mathrm{dm}^{-2} \mathrm{hr}^{-1 / 2}$. Assuming non-selective oxidation and recrystallization of all excess $\mathrm{Ni}(\mathrm{II})$ as $\mathrm{Ni}$, allows the oxide formation constant to be converted to $\mathrm{k}_{\mathrm{p}}=0.055 \mathrm{mg}$ (alloy) $\mathrm{dm}^{-2}$ $\mathrm{hr}^{-1 / 2}$, a value in agreement with the gravimetric result. It is noted that this conversion also assumes that contributions from corrosion release and iron pickup are negligible (or offsetting). 
Table IV also includes compositions of the Alloy 600 substrate determined from XPS recorded for $\mathrm{Ni}(2 p), \mathrm{Cr}(2 p)$ and $\mathrm{Fe}(3 p)$ at large sputter depths where $\mathrm{O}(1 \mathrm{~s})$ ö 0 . The results compare well with the (known) chemical composition of $\mathrm{NiCrFe}$ Alloy 600 and serve as a self-consistency check on the accuracy of the experimental methodology.

The above oxide thickness estimates were then speciated by TFA; the resulting speciated profiles for the 5000 and 10,000 hr specimens being shown in the lower portions of Figs. 6 and 7, respectively. All speciated profiles were then integrated numerically and multiplied by a spinel oxide density of $5.22 \mathrm{~g} / \mathrm{cm}^{3}$ to obtain a surface oxide density in $\mathrm{mg} / \mathrm{dm}^{2}$; see Table V. Metal density was assumed to be that of the base alloy $\left(=8.51 \mathrm{~g} / \mathrm{cm}^{3}\right.$ for Alloy 600$)$. Composition of the metal in closest contact with the spinel oxide layer tended to be slightly elevated in its nickel content relative to Alloy 600 , consistent with the presence of small amounts of a recrystallized nickel phase.

Overall composition of the corrosion oxide layer is $\left(\mathrm{Ni}_{0.76} \mathrm{Fe}_{0.24}\right)\left(\mathrm{Fe}_{0.38} \mathrm{Cr}_{0.62}\right)_{2} \mathrm{O}_{4}$. This corresponds to a mixed chromite (60\%) - ferrite (40\%) spinel, which places the composition in an immiscible region of the nickel ferrite-nickel chromite spinel binary. As shown in Table VI, composition of the corrosion oxide is not uniform with depth: oxide closest to the water interface tends to be ferrite-enriched, while oxide interfacing with the alloy tends to be chromite-enriched. The overall test averages are:

$$
\begin{aligned}
& \text { Outer Layer }-\left(\mathrm{Ni}_{0.9} \mathrm{Fe}_{0.1}\right)\left(\mathrm{Fe}_{0.55} \mathrm{Cr}_{0.45}\right)_{2} \mathrm{O}_{4} \\
& 55 \mathrm{~mol} \% \text { ferrite }-45 \mathrm{~mol} \% \text { chromite } \\
& \text { Inner Layer }-\left(\mathrm{Ni}_{0.7} \mathrm{Fe}_{0.3}\right)\left(\mathrm{Fe}_{0.3} \mathrm{Cr}_{0.7}\right)_{2} \mathrm{O}_{4}
\end{aligned}
$$




\section{0 mol \% chromite -30 mol \% ferrite}

Due to inhomogeneity of the ferrite layer, i.e., incomplete surface coverage, the outer layer composition inferred from XPS/ion milling includes a chromite contribution from the (partially uncovered) inner layer. Thus, the actual outer layer composition contains a higher ferrite content than indicated by XPS; a more accurate estimate of the outer layer composition being obtained from the EDX analyses performed in conjunction with SEM and TEM: $\left(\mathrm{Ni}_{0.9} \mathrm{Fe}_{0.1}\right)$ $\left(\mathrm{Fe}_{0.85} \mathrm{Cr}_{0.15}\right)_{2} \mathrm{O}_{4}$, i.e., $85 \mathrm{~mol} \%$ ferrite.

In a similar manner, XPS/ion milling may underestimate chromite composition of the inner layer. This possibility is suggested by the decreasing trend in inner layer chromite levels as function of exposure time and the presence of elongated tails in the oxygen profiles mentioned previously. This behavior is illustrated by comparing Figs. 8a and b. Such an effect occurs when relatively large amounts (size and number density) of outer layer ferrite crystals are present. Thus, significant remnants of the outer layer ferrites were still being analyzed at indicated sputter depths greater than the inner layer thickness. The presence of this bias was further confirmed by mechanically removing the outer layer crystals on selected specimens (via abrasion with a pencil eraser) and subjecting the specimens to a repeat XPS/ion milling analysis to determine the composition of the remaining (inner) corrosion oxide layer. As shown in Fig. 8c, the estimated $\mathrm{Cr}(\mathrm{III})$ composition of the inner layer, in the absence of ferrite layer interference, is $70 \mathrm{~mol} \%$ chromite.

In summary, SEM/TEM, GIXRD and XPS examinations of corroded NiCrFe Alloy 600 surfaces reveal the presence of a duplex corrosion oxide layer having the estimated compositions: 
$\left(\mathrm{Ni}_{0.9} \mathrm{Fe}_{0.1}\right)\left(\mathrm{Fe}_{1-\mathrm{x}} \mathrm{Cr}_{\mathrm{x}}\right)_{2} \mathrm{O}_{4}, \mathrm{x}=0.15$ (outer oxide) and $\left(\mathrm{Ni}_{0.7} \mathrm{Fe}_{0.3}\right)\left(\mathrm{Fe}_{1-\mathrm{x}} \mathrm{Cr}_{\mathrm{x}}\right)_{2} \mathrm{O}_{4}, \mathrm{x}=0.70$ (inner oxide). Evidence for the presence of recrystallized nickel metal was inconclusive: none was found by GIXRD although the XPS analyses provided positive indications.

\section{DISCUSSION}

\section{A. Kinetics of NiCrFe Alloy 600 Corrosion}

The corrosion rates of pure metals, being controlled by the migration of ions and vacancies in the oxide lattice, are expected to follow a general 'sinh law' model [18]. Two limiting cases: inverse logarithmic kinetics (thin film) and parabolic kinetics (thick film), as well as an intermediate case (approximately cubic) are possible. Presently, the long exposure times make the thick film model appropriate, although it is not possible to predict the distribution of corroded alloying constituents. Correlation of the parabolic rate constant $\left(\mathrm{K}_{\mathrm{p}}\right)$ with those reported previously for Alloy 600 in hydrogenated water at higher temperatures [19]: 0.489 and $2.12 \mathrm{mg}$ alloy $\mathrm{dm}^{-2} \mathrm{hr}^{-1 / 2}$ at 325 and $350^{\circ} \mathrm{C}$, respectively, provides an Arrhenius activation energy of $110 \mathrm{~kJ} \mathrm{~mol}^{-1}$, see Fig. 9.

Perhaps the most significant result of the present study is that nickel, which comprises $3 / 4$ of the metals present, represents less than $1 / 3$ of the oxidized metals. The absence of a separate nickel oxide phase is consistent with a shift in the redox equilibrium to the right for

$$
\mathrm{NiO}(\mathrm{s})+\mathrm{H}_{2}(\mathrm{~g}) \quad \mathrm{Ni}(\mathrm{s})+\mathrm{H}_{2} \mathrm{O}
$$

due to the presence of dissolved hydrogen. It may, in fact, be predicted that only 2-3 scm ${ }^{3} \mathrm{H}_{2} / \mathrm{kg}$ water are required to reduce $\mathrm{NiO}$ to nickel metal in $260^{\circ} \mathrm{C}$ water using available thermodynamic properties [20]. Although corrosion of nickel and nickel base alloys in oxygenated water is 
believed to be controlled by oxygen diffusion through a porous nickel(II) oxide layer [21], the anodic (i.e., oxidation) reaction in deaerated and hydrogenated waters shifts to a potential near that of the reference hydrogen electrode [22]. Not only are decreased corrosion rates observed in these instances, but the corrosion rates become limited by hydrogen formation (i.e., the cathodic reaction) [21].

\section{B. Characteristics of Corrosion Layer}

The XPS/TFA results demonstrate that Alloy 600 corrodes by forming a fine-grained, chromiterich (inner) oxide layer having the approximate composition $\left(\mathrm{Ni}_{0.7} \mathrm{Fe}_{0.3}\right)\left(\mathrm{Fe}_{0.3} \mathrm{Cr}_{0.7}\right)_{2} \mathrm{O}_{4}$. This oxide phase is believed to form during the inward penetration of oxygen and occurs simultaneously with the outward migration of predominately nickel (and iron) cations to maintain a constant volume condition. Ferrite-chromite immiscibility also plays a role in the separation phenomenon.

Because the $\mathrm{Cr} / \mathrm{Fe}$ ratio in Alloy 600 is close to that of the chromite-rich solvus expected in the nickel chromite-nickel ferrite spinel binary, non-selective oxidation of the alloy is expected to produce relatively minor amounts of the outer, ferrite-rich solvus layer. Given the overall composition of the corrosion oxide found by XPS in Table V $(41 \mathrm{~mol} \% \mathrm{Cr})$ and the measured compositions of the inner $(47 \mathrm{~mol} \% \mathrm{Cr})$ and outer $(10 \mathrm{~mol} \% \mathrm{Cr})$ layers in Table VI, the mass ratio of outer-to-inner layer oxide is 0.20 , in agreement with expectations.

The total iron composition of the spinel oxides found by XPS, however, reveals an excess of oxidized iron, which could result from: (1) pickup of non-indigenous iron dissolved in the 
aqueous phase, or (2) selective oxidation of the alloy. Since the gravimetric analyses also found unaccounted increases in weight during corrosion, the first interpretation is believed to be correct.

Material balances for oxidized chromium and iron were performed using results from the integrated XPS composition profiles and the alloy corrosion rate assuming non-selective oxidation, see Table VII. All of the oxidized chromium is accounted for (i.e., its material balance closes to within $0.2 \mathrm{mg} \mathrm{dm}^{-2}$ ), while an excess of oxidized iron exists (i.e., more is present in the oxide layer than was created during corrosion). The excess iron increases with exposure time, in agreement with specimen weight increases during corrosion in Table I. Thus, the creation of minor amounts of an outer, ferrite-rich solvus layer is consistent with a nonselective oxidation accompanied by iron pickup from the aqueous phase.

A summary of corrosion oxide and substrate compositions is given in Table VIII for the three FeNiCr alloys characterized to date. This comparison reveals that the $\mathrm{Fe}(\mathrm{III})-\mathrm{Cr}(\mathrm{III})$ ion composition of the chromite-rich, inner layer oxide on all three alloys is the same, as is the composition of the ferrite-rich, outer layer oxide; the major difference being the higher $\mathrm{Ni}(\mathrm{II}) / \mathrm{Fe}(\mathrm{II})$ ion ratio in the outer layer oxide on the nickel base alloys. Therefore, these results support the hypothesized, invariant nature of the oxides as solvi in the immiscible spinel binary $\mathrm{Fe}_{3} \mathrm{O}_{4}-\mathrm{FeCr}_{2} \mathrm{O}_{4}$ (or $\mathrm{NiFe}_{2} \mathrm{O}_{4}-\mathrm{NiCr}_{2} \mathrm{O}_{4}$ ). Because the divalent cations are dominated by $\mathrm{Ni}(\mathrm{II})$ in the nickel-based alloy, rather than $\mathrm{Fe}$ (II) as in the iron-based alloy, solvi in the $\mathrm{NiFe}_{2} \mathrm{O}_{4}-\mathrm{NiCr}_{2} \mathrm{O}_{4}$ binary provide a more accurate model for predicting trivalent cation compositions of the inner 
and outer oxide layers on nickel-based CrFe alloys. Presently, experimental solvi in the $\mathrm{NiFe}_{2} \mathrm{O}_{4}-\mathrm{NiCr}_{2} \mathrm{O}_{4}$ binary are being obtained in our laboratory and will be reported at a later date.

\section{C. $\quad$ Corrosion Release Behavior}

Closure of the material balance for nickel is more complex since three end-states for Ni(II) ion placement need to be considered: (1) incorporation into the corrosion oxide spinel, (2) recrystallization as elemental nickel and (3) loss to the aqueous phase by dissolution/release. In order to retain the non-selective corrosion hypothesis, Table IX shows that a selective release of Ni(II) ions to the aqueous phase must be recognized; the XPS results providing an average release rate of $36 \%$. That is, approximately $1 / 3$ of the corroded nickel was released to the aqueous phase.

The above results are in approximate agreement with a second estimate of corrosion release obtained by analyzing specimen weight changes during testing (Table I) as corrected for iron (and oxygen) pickup (Table VII). Note that the uncorrected 1000 and $2000 \mathrm{hr}$ gravimetric results, where iron pickup is insignificant, indicate a corrosion release rate of $65 \%$. Converting the $0.9 \mathrm{mg}$ iron $\mathrm{dm}^{-2}$ pickup estimate at $10,000 \mathrm{hr}$ to a specimen weight increase of $0.53 \mathrm{mg}$ (i.e., iron and oxygen) produces a release of $0.77 \mathrm{mg}$ nickel, which corresponds to a corrosion release rate of 33\%. Thus, Alloy 600 experienced selective corrosion release of nickel during the present test. Such high values of corrosion release are consistent with the results of previous investigations where release values as high as 50\% were reported $[19,23]$.

\section{Limiting Nickel(II) Ion Stoichiometry of Ferrite-Rich Solvus}


Finally, it is noted that the divalent cation composition of the outer layer spinel on Alloy 600 is not that of stoichiometric nickel ferrite, but contains $10 \mathrm{~mol} \% \mathrm{Fe}(\mathrm{II})$. This departure from stoichiometric ideality is believed to be a consequence of $\mathrm{Ni}$ (II) ion reduction in the presence of dissolved hydrogen. The applicable thermodynamic equilibrium to be satisfied is

$$
\begin{aligned}
& \mathrm{NiFe}_{2} \mathrm{O}_{4}(s)+(4 / 3) \mathrm{H}_{2}(g) \underset{\leftarrow}{\rightleftarrows} \mathrm{Ni}(s)+(2 / 3) \mathrm{Fe}_{3} \mathrm{O}_{4}(s)+(4 / 3) \mathrm{H}_{2} \mathrm{O} \\
& K_{e q}=\frac{(\mathrm{Ni})\left(\mathrm{Fe}_{3} \mathrm{O}_{4}\right)^{2 / 3}\left(\mathrm{H}_{2} \mathrm{O}\right)^{4 / 3}}{\left(\mathrm{NiFe}_{2} \mathrm{O}_{4}\right)\left(\mathrm{H}_{2}\right)^{4 / 3}}
\end{aligned}
$$

If it is assumed that the non-stoichiometric nickel ferrite formed by the above reaction, $\left(\mathrm{Ni}_{\mathrm{y}} \mathrm{Fe}_{1-\mathrm{y}}\right)$ $\mathrm{Fe}_{2} \mathrm{O}_{4}$, is an ideal solid solution of $\mathrm{Fe}_{3} \mathrm{O}_{4}$ and $\mathrm{NiFe}_{2} \mathrm{O}_{4}$, then $\left(\mathrm{NiFe}_{2} \mathrm{O}_{4}\right)=\mathrm{y}$ and $\left(\mathrm{Fe}_{3} \mathrm{O}_{4}\right)=1-\mathrm{y}$. This analysis provides

$$
K_{e q}\left(P_{H 2}\right)^{4 / 3}={\frac{(1-y)^{2 / 3}}{y}}^{2 / 3}
$$

which can be solved for $\mathrm{y}$ as a function of temperature and dissolved hydrogen concentration. Using available thermochemical property tabulations [20] and Henry's law coefficient for hydrogen in water [24], y is calculated to be 0.89 at $260^{\circ} \mathrm{C}$ for a dissolved hydrogen concentration of $45 \mathrm{scc} / \mathrm{kg}$. In other words, dissolved hydrogen limits the nickel stoichiometry of nickel ferrite, $\left(\mathrm{Ni}_{\mathrm{y}} \mathrm{Fe}_{1-\mathrm{y}}\right) \mathrm{Fe}_{2} \mathrm{O}_{4}$, to a maximum around $\mathrm{y}=0.9$. Thus, good agreement is demonstrated between the predicted and measured distribution of $\mathrm{Fe}(\mathrm{II})$ and $\mathrm{Ni}$ (II) ions in the ferrite-rich solvus.

\section{$\underline{\text { ACKNOWLEDGEMENT }}$}

The professional assistance of the following individuals contributed to the successful execution of the experimental program: R. R. Shaulis, for test operation; G. M. Neugebauer, for high 
resolution SEM; N. Lewis, for TEM/EDX analyses; Y. Gao (GE Corporate R\&D Center), for GIXRD; and B. A. Tatanus, for chemical descale analyses.

\section{$\underline{\text { REFERENCES }}$}

1. S.E. Ziemniak and M. Hanson, Corros. Sci. 44, 2209 (2002)

2. S. E. Ziemniak and R. A. Castelli, J. Phys. Chem. Solids 64, 2081 (2003)

3. S. E. Ziemniak and M. Hanson, Corros. Sci. $\underline{45}, 1595$ (2003)

4. G.H. Vineyard, Phys. Rev. B26, 4146 (1982)

5. M.F. Toney, T.C. Huang, S. Brennan and Z. Rek, J. Mater. Res. $\underline{3}$, 351 (1988)

6. R. Jenkins and R.L. Snyder, Introduction to X-Ray Powder Diffraction, John Wiley \& Sons, New York, 1996.

7. A. Savitzky and M.J.E. Golay, Anal. Chem. 36, 8 (1964)

8. D.A. Shirley, Phys. Rev. B5, 4709 (1972)

9. K.M. Ostyn and C.B. Carter, Surface Sci. 121, 360 (1982)

10. M.A. Langell, Surface Sci. 186, 323 (1987)

11. A.R. Gonzalez-Elipe, R. Alvarez, J.P. Espinos and G. Munuera, Appl. Surface Sci. 51, 19 (1991)

12. E.R. Malinowski, Factor Analysis in Chemistry, John Wiley \& Sons, NY (1991)

13. JCPDS Powder Diffraction File, International Centre for Diffraction Data, Swarthmore, PA, 1989

14. H.P. Klug and L.E. Alexander, $\underline{X-R a y ~ D i f f r a c t i o n ~ P r o c e d u r e s, ~} 2^{\text {nd }}$ ed., Wiley Interscience, New York (1974)

15. G. Lim, W. Parrish and C. Ortiz, J. Mater. Res. $\underline{2}$, 471 (1987)

16. G. C. Allen, J. A. Jutson and P. A. Tempest, J. Nucl. Mat. 158, 96 (1988)

17. P. Swift, Surf. Interf. Anal. $\underline{4}, 47$ (1982)

18. U.R. Evans, Corrosion and Oxidation of Metals, Arnold, London (1960)

19. L. Guinard, O. Kerrec, D. Noel, S. Gardley and F. Coulet, Nucl. Energy $\underline{36}, 19$ (1997)

20. D.D. Wagman, W.H. Evans, V.B. Parker, R.H. Schumm, I. Halow, S.M. Bailey, K.L. Churney and R.L. Nuttall, J. Phys. Chem. Ref. Data 11, Suppl. 2 (1982)

21. M. Yasuda, K. Fukumoto, Y. Ogata and F. Hine, J. Electrochem. Soc. 135, 2982 (1988) 
22. M.E. Indig and C. Groot, Corrosion 26, 171 (1970)

23. J. Robertson, in: Water Chemistry of Nuclear Reactor Systems 5, British Nuclear Energy Society, London, 1989, p. 81

24. R. Fernandez-Prini and R. Crovetto, J. Phys. Chem. Ref. Data $\underline{18}$, 1231 (1989) 


\section{TABLE I}

Alloy 600 Corrosion and Release/Pickup Estimates Obtained by Gravimetric Analyses

Weight Change Base Metal Zero Release ${ }^{\text {a }} \quad$ Pickup -

Exposure Time, $\mathrm{hr}$ During Test, mg Oxidized,mg Wgt change, mg Release, mg

$\begin{array}{ccccc}1000 & -0.41 \pm 0.19 & 0.64 \pm 0.11 & 0.12 & -0.53 \\ 2000 & -0.52 \pm 0.26 & 0.97 \pm 0.05 & 0.18 & -0.70 \\ 3000 & -0.39 \pm 0.34 & - & & \\ 5000 & -0.40 \pm 0.30 & 1.71 \pm 0.16 & 0.31 & -0.71 \\ 5000^{\mathrm{c}} & +0.30 \pm 0.34 & 1.00 \pm 0.13 & 0.18 & 0.12 \\ 8,000 & +0.79 \pm 0.51 & \mathrm{~b} & 0.34 & 0.45 \\ 10,000 & +0.19 \pm 0.40 & 2.36 \pm 0.27 & 0.43 & -0.24\end{array}$

a $\quad 0.184 \times$ column III, see text.

b Invalid result caused by excessive attack of unoxidized base alloy by descale solutions; estimated value from data correlation $=1.86 \mathrm{mg}$.

c Specimens exposed during second $5000 \mathrm{hr}$ of test period. 
TABLE II

Spinel Composition $\left(\mathrm{Ni}_{\mathrm{y}} \mathrm{Fe}_{1-\mathrm{y}}\right)\left(\mathrm{Fe}_{2-\mathrm{x}} \mathrm{Cr}_{\mathrm{x}}\right) \mathrm{O}_{4}$ of Oxide Crystals Formed on Alloy 600 as Determined by EDX Microanalyses

\begin{tabular}{cccccc}
\hline Specimen/ & \multicolumn{3}{c}{ Atom \%, Normalized } & \multicolumn{2}{c}{ Stoichiometry } \\
Exposure hr & $\mathrm{Fe}$ & $\mathrm{Cr}$ & $\mathrm{Ni}$ & $\mathrm{y}$ & $\mathrm{x}$ \\
\hline I89/8000(a) & 80.6 & 1.0 & 18.4 & 0.55 & 0.03 \\
& 65.9 & 6.6 & 27.5 & 0.82 & 0.20 \\
I93/8000(a) & 70.4 & 1.2 & 28.4 & 0.85 & 0.04 \\
& 63.0 & 7.0 & 30.0 & 0.90 & 0.21 \\
& 66.2 & 14.1 & 29.7 & $\underline{0.89}$ & $\underline{0.42}$ \\
& & & & & \\
& & & & & \\
I67/10,000(b) & 64 & 8 & 28 & 0.80 & 0.18 \\
$\begin{array}{c}\text { (large crystals) } \\
\text { I67/10,000(b) }\end{array}$ & 33 & 39 & 28 & 0.85 & 0.2 \\
(small crystals) & & & & & \\
\hline
\end{tabular}

Notes: (a) Removed prior to EDX using replicating tape.

(b) In-situ EDX of selected areas in Fig. 3 (TEM). 
TABLE III

Indexed GIXRD Peaks for Corroded Alloy 600 Specimen (AX05, 10,000 hrs), $\left(\phi=0.5^{\circ}\right)$

\begin{tabular}{|c|c|c|c|c|c|}
\hline \multirow{2}{*}{$\begin{array}{l}\text { Reflection Plane } \\
\text { Indices, hkl }\end{array}$} & \multicolumn{5}{|c|}{ Reflection Plane } \\
\hline & $2 \theta_{\text {obs }}$ & $2 \theta_{\text {cor }}$ & Indices, hkl & $2 \theta_{\text {obs }}$ & $2 \theta_{\text {cor }}$ \\
\hline \multicolumn{3}{|c|}{ Spinel Phase } & \multicolumn{3}{|c|}{ Nickel (Alloy) Phase } \\
\hline 220 & 22.488 & 22.427 & & & \\
\hline 311 & 26.434 & 26.374 & & & \\
\hline 222 & 27.630 & 27.570 & & & \\
\hline 400 & 32.014 & 31.954 & 111 & 32.550 & 32.490 \\
\hline 422 & 39.476 & 39.416 & 200 & 37.689 & 37.629 \\
\hline 511 & 41.987 & 41.927 & & & \\
\hline 440 & 45.914 & 45.855 & & & \\
\hline 620 & 51.693 & 51.634 & & & \\
\hline 533 & 53.753 & 53.694 & 220 & 54.415 & 54.356 \\
\hline 444 & 57.063 & 57.004 & & & \\
\hline 642 & 62.124 & 62.065 & & & \\
\hline 731 & 63.954 & 63.895 & 311 & 64.809 & 64.750 \\
\hline 800 & 66.949 & 66.890 & & & \\
\hline \multicolumn{2}{|c|}{ Lattice Parameter $\left(a_{0}, D\right)$} & $8.3507(10)$ & \multicolumn{2}{|c|}{ Lattice Parameter $\left(a_{0}, D\right)$} & $8.5621(8)$ \\
\hline
\end{tabular}




\section{TABLE IV}

Surface Oxide Layer Thickness (D) on Alloy 600 Based on Intensity of O(ls) XPS Peak and Inferred Substrate Composition at Large Sputter Depths (Oxygen $<5$ at.\%)

\begin{tabular}{|c|c|c|c|c|}
\hline \multirow{2}{*}{$\begin{array}{l}\text { Exposure time, } \mathrm{hr}^{\mathrm{b}} \\
\text { (specimen id.) }\end{array}$} & \multirow{2}{*}{$\begin{array}{l}\text { O(1s) depth, } \\
\text { D }\end{array}$} & \multicolumn{3}{|c|}{ Elemental distribution, wgt. \% } \\
\hline & & $\mathrm{Ni}$ & $\mathrm{Cr}$ & $\mathrm{Fe}$ \\
\hline 1000 (I85) & 162 & 76.0 & 17.2 & 6.8 \\
\hline 1500 (I53) & 152 & 76.3 & 16.6 & 7.1 \\
\hline 2000 (I77) & 171 & 75.1 & 17.5 & 7.4 \\
\hline 2500 (I51) & 229 & 75.7 & 17.2 & 7.1 \\
\hline 5000 (I75) & 448 & 77.0 & 17.3 & 5.7 \\
\hline 5000 (I99) & 417 & 75.9 & 17.5 & 6.6 \\
\hline 5500 (I47) & 267 & 74.8 & 16.9 & 8.3 \\
\hline 5500 (I63) & 408 & 74.6 & 18.4 & 7.0 \\
\hline 8000 (I89) & 598 & \multicolumn{3}{|c|}{ (insufficient asymptote) } \\
\hline 8500 (I59) & 531 & \multicolumn{3}{|c|}{ (insufficient asymptote) } \\
\hline 10,000 (I67) & $(1000)^{c}$ & 73.4 & 17.2 & 9.4 \\
\hline \multirow[t]{2}{*}{10,500 (I43) } & 495 & \multicolumn{3}{|c|}{ (insufficient asymptote) } \\
\hline & Avg: & $75.5 \pm 1.0$ & $17.4 \pm 0.5$ & $7.1 \pm 1.0$ \\
\hline & of Alloy $600^{\mathrm{d}}$ : & 74.0 & 16.1 & 9.0 \\
\hline \multicolumn{5}{|c|}{$\begin{array}{l}\text { b Specimens having exposures ending in } 500 \text { hrs were installed } 500 \text { hours prior to official star } \\
\text { of test. }\end{array}$} \\
\hline
\end{tabular}


TABLE V

NiCrFe Alloy 600 Corrosion Film Characterization by Integration of Speciated XPS Composition vs. Depth Profiles

\begin{tabular}{|c|c|c|c|c|c|}
\hline \multirow[b]{2}{*}{$\begin{array}{l}\text { Exposure } \\
\text { Time, hrs. }\end{array}$} & \multirow{2}{*}{$\begin{array}{l}\text { Metal Ion } \\
\text { Content, } \\
\mathrm{mg} \mathrm{dm}^{-2}\end{array}$} & \multicolumn{3}{|c|}{ Distribution, wgt $\%$} & \multirow{2}{*}{$\begin{array}{c}\text { Recrys. } \\
\mathrm{Ni}, \\
\mathrm{mg} \mathrm{dm}^{-2}\end{array}$} \\
\hline & & $\mathrm{Ni}(\mathrm{II})$ & $\mathrm{Cr}(\mathrm{III})$ & $\mathrm{Fe}(\mathrm{II}, \mathrm{III})$ & \\
\hline 1000 (I85) & 0.84 & 36.9 & 39.3 & 23.8 & 0.91 \\
\hline 1500 (I53) & 0.64 & 32.8 & 45.3 & 21.9 & 0.58 \\
\hline 2000 (I77) & 1.28 & 25.8 & 45.3 & 28.9 & 1.05 \\
\hline 2500 (I51) & 0.94 & 22.3 & 50.0 & 27.7 & 0.76 \\
\hline 5000 (I75) & 2.04 & 29.4 & 38.7 & 31.9 & 0.77 \\
\hline 5000 (I99) & 2.74 & 35.0 & 29.2 & 35.8 & 1.03 \\
\hline 5500 (I47) & 1.39 & 28.1 & 42.4 & 29.5 & 0.82 \\
\hline 5500 (I63) & 3.89 & 33.4 & 26.2 & 40.4 & 1.55 \\
\hline 8000 (I89) & 2.58 & 23.6 & 36.8 & 39.5 & 0.97 \\
\hline 8500 (I59) & 2.23 & 20.6 & 36.8 & 42.6 & 0.75 \\
\hline 10,000 (I67) & 3.85 & 26.0 & 34.5 & 39.5 & 1.12 \\
\hline 10,500 (I43) & 3.11 & $\underline{22.8}$ & $\underline{36.0}$ & $\underline{41.2}$ & 0.74 \\
\hline & Avg. & 27.6 & 38.8 & 33.7 & \\
\hline
\end{tabular}




\section{TABLE VI}

Spinel Composition $\left(\mathrm{Ni}_{\mathrm{y}} \mathrm{Fe}_{1-\mathrm{y}}\right)\left(\mathrm{Fe}_{2-\mathrm{x}} \mathrm{Cr}_{\mathrm{x}}\right) \mathrm{O}_{4}$ of Surface and Inner Corrosion Film on Alloy 600

\begin{tabular}{ccccc}
\hline Exposure Time, hrs & \multicolumn{2}{c}{ Surface Layer } & \multicolumn{2}{c}{ Inner Layer } \\
& \multicolumn{1}{c}{$\mathrm{y}$} & $\mathrm{x}$ & $\mathrm{y}$ & $\mathrm{x}$ \\
\hline 1000 (I85) & 1.0 & 0.6 & 0.8 & 1.4 \\
1500 (I53) & 1.0 & 0.8 & 0.5 & 1.8 \\
2000 (I77) & 0.9 & 1.1 & 0.7 & 1.55 \\
2500 (I51) & 1.0 & 1.1 & 0.5 & 1.7 \\
$5000(\mathrm{I} 75)$ & 1.0 & 0.7 & 0.8 & 1.35 \\
5000 (I71) & 1.0 & 0.6 & 0.65 & 1.45 \\
5500 (I47) & 1.0 & 0.8 & 0.7 & 1.5 \\
8000 (I89) & 0.7 & 1.0 & 0.7 & 1.2 \\
8500 (I59) & 0.7 & 1.0 & 0.6 & 1.2 \\
10,000 (I67) & 0.75 & 0.85 & 0.6 & 1.2 \\
10,500 (I43) & 0.7 & 1.1 & 0.6 & 1.2 \\
avg: & $\left(\mathrm{Ni}_{0.9} \mathrm{Fe}_{0.1}\right)\left(\mathrm{Fe}_{0.55} \mathrm{Cr}_{0.45}\right)_{2} \mathrm{O}_{4}{ }^{\mathrm{d}}$ & $\left(\mathrm{Ni}_{0.7} \mathrm{Fe}_{0.3}\right)\left(\mathrm{Fe}_{0.3} \mathrm{Cr}_{0.7}\right)_{2} \mathrm{O}_{4}{ }^{\mathrm{e}}$
\end{tabular}

${ }^{d}$ Expected bias in $\mathrm{Cr}(\mathrm{III})$ result due to inclusion of inner layer $\mathrm{Cr}$ (III) in surface oxide XPS signal. See discussion in text.

${ }^{\mathrm{e}}$ Corrected for interference from larger, outer layer ferrite crystals. 


\section{TABLE VII}

Material Balances for Chromium and Iron During Corrosion of NiCrFe Alloy 600

\begin{tabular}{cccccc}
\hline $\begin{array}{c}\text { Exposure } \\
\text { Time, hr }\end{array}$ & $\begin{array}{c}\mathrm{Cr}(\mathrm{III}), \mathrm{mg} \mathrm{dm}^{-2} \\
\text { Corroded } \\
\text { per Table I }\end{array}$ & $\begin{array}{c}\text { Found in } \\
\text { Scale (Table V) }\end{array}$ & $\begin{array}{c}\text { Fe(II, III), } \mathrm{mg} \mathrm{dm}^{-2} \\
\text { Corroded* } \\
\text { per Table I }\end{array}$ & $\begin{array}{c}\text { Found in } \\
\text { Scale (Table V) }\end{array}$ & $\begin{array}{c}\text { Difference,** } \\
\mathrm{mg} \mathrm{dm}^{-2}\end{array}$ \\
\hline 1000(I85) & 0.28 & 0.33 & 0.16 & 0.20 & 0.04 \\
1500 (I53) & 0.34 & 0.29 & 0.19 & 0.14 & -0.05 \\
2000(I77) & 0.40 & 0.58 & 0.22 & 0.37 & 0.15 \\
2500(I51) & 0.44 & 0.47 & 0.25 & 0.26 & 0.01 \\
5000 (I75) & 0.63 & 0.79 & 0.35 & 0.65 & 0.30 \\
5000 (I99) & 0.63 & 0.80 & 0.35 & 0.98 & 0.63 \\
5500 (I47) & 0.66 & 0.59 & 0.37 & 0.41 & 0.04 \\
5500 (I63) & 0.66 & 1.02 & 0.37 & 1.57 & 1.20 \\
8000 (I89) & 0.79 & 0.95 & 0.44 & 1.02 & 0.58 \\
8500 (I59) & 0.82 & 0.82 & 0.46 & 0.95 & 0.49 \\
10,000 (I67) & 0.89 & 1.33 & 0.50 & 1.52 & 1.02 \\
10,500 (I43) & 0.91 & 1.12 & 0.51 & 1.28 & 0.77
\end{tabular}

* Non-selective oxidation hypothesis applied to parabolic correlation $0.055 \mathrm{t}^{1 / 2}$.

** Positive value indicates pickup. 
TABLE VIII

Corrosion Oxide and Substrate Compositions of Select FeNiCr Alloys

\begin{tabular}{|c|c|c|}
\hline Alloy/Composition & Inner oxide & Outer oxide \\
\hline $\begin{array}{l}\text { Alloy } 600 \\
\text { Ni-base } 16 \mathrm{Cr} 9 \mathrm{Fe}\end{array}$ & $\left(\mathrm{Ni}_{0.7} \mathrm{Fe}_{0.3}\right)\left(\mathrm{Fe}_{0.3} \mathrm{Cr}_{0.7}\right)_{2} \mathrm{O}_{4}$ & $\left(\mathrm{Ni}_{0.9} \mathrm{Fe}_{0.1}\right)\left(\mathrm{Fe}_{0.85} \mathrm{Cr}_{0.15}\right)_{2} \mathrm{O}_{4}$ \\
\hline $\begin{array}{l}\text { Alloy } 625[3] \\
\text { Ni-base } 22 \mathrm{Cr}^{2} \mathrm{Fe}^{*}\end{array}$ & $\left(\mathrm{Ni}_{0.7} \mathrm{Fe}_{0.3}\right)\left(\mathrm{Fe}_{0.2} \mathrm{Cr}_{0.8}\right)_{2} \mathrm{O}_{4}$ & $\left(\mathrm{Ni}_{0.9} \mathrm{Fe}_{0.1}\right)\left(\mathrm{Fe}_{0.9} \mathrm{Cr}_{0.1}\right)_{2} \mathrm{O}_{4}$ \\
\hline $\begin{array}{l}304 \mathrm{SS}[1] \\
\text { Fe-base } 18 \mathrm{Cr} 8 \mathrm{Ni}\end{array}$ & $\left(\mathrm{Ni}_{0.2} \mathrm{Fe}_{0.8}\right)\left(\mathrm{Fe}_{0.3} \mathrm{Cr}_{0.7}\right)_{2} \mathrm{O}_{4}$ & $\left(\mathrm{Ni}_{0.2} \mathrm{Fe}_{0.8}\right)\left(\mathrm{Fe}_{0.95} \mathrm{Cr}_{0.05}\right)_{2} \mathrm{O}_{4}$ \\
\hline $\begin{array}{l}\text { Solvi in } \\
\mathrm{Fe}_{3} \mathrm{O}_{4} / \mathrm{FeCr}_{2} \mathrm{O}_{4} \\
\text { spinel binary [2] }\end{array}$ & $\mathrm{Fe}\left(\mathrm{Fe}_{0.35} \mathrm{Cr}_{0.65}\right)_{2} \mathrm{O}_{4}$ & $\mathrm{Fe}\left(\mathrm{Fe}_{0.85} \mathrm{Cr}_{0.15}\right)_{2} \mathrm{O}_{4}$ \\
\hline
\end{tabular}

* Alloy 625 also contains 10\% Mo and 4\% Nb. 


\section{TABLE IX}

Material Balance for Nickel Oxidized During Corrosion of NiCrFe Alloy 600

\begin{tabular}{|c|c|c|c|c|c|}
\hline \multirow[b]{2}{*}{$\begin{array}{l}\text { Exposure } \\
\text { Time, hrs }\end{array}$} & \multicolumn{4}{|c|}{$\mathrm{Ni}(\mathrm{II}), \mathrm{mg} \mathrm{dm}^{-2}$} & \multirow[b]{2}{*}{$\begin{array}{c}\text { Corrosion } \\
\text { Release }^{\mathrm{a}}, \% \\
\end{array}$} \\
\hline & $\begin{array}{c}\text { Produced by } \\
\text { Corrosion (Table I) }\end{array}$ & $\begin{array}{c}\text { Found in } \\
\text { Scale (Table V) }\end{array}$ & $\begin{array}{l}\text { Recrys. Ni }(0) \\
\text { (Table V) }\end{array}$ & Loss & \\
\hline 1000 & 1.29 & 0.30 & 0.91 & 0.08 & 6 \\
\hline 2000 & 1.83 & 0.32 & 1.05 & 0.45 & 25 \\
\hline 5000 & 2.88 & 0.78 & 0.90 & 1.20 & 42 \\
\hline 8000 & 3.64 & 0.61 & 0.97 & 2.06 & 57 \\
\hline 10,000 & 4.07 & 1.00 & 1.12 & 1.95 & 48 \\
\hline & & & & & $36 \pm 18$ \\
\hline
\end{tabular}

${ }^{a}$ Column V/ Column II. 
(a)

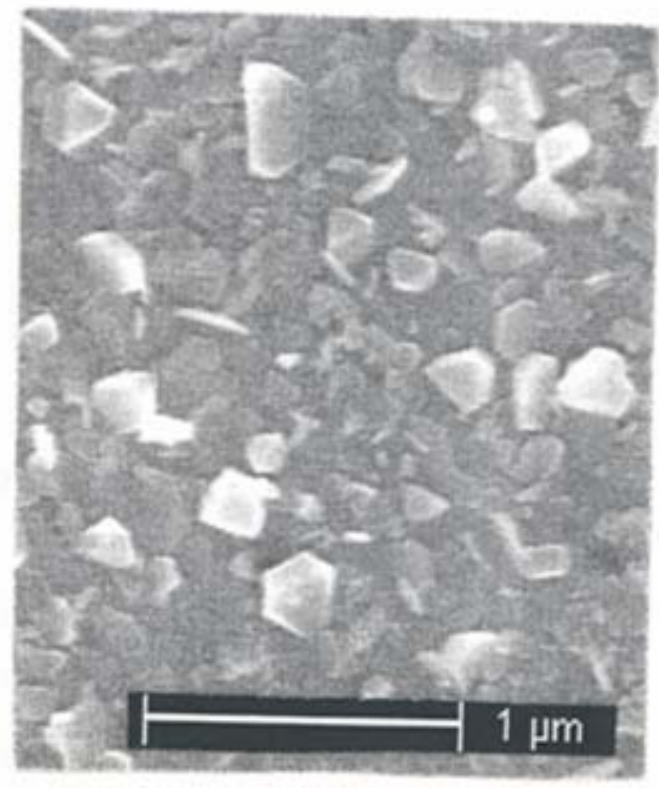

(c)

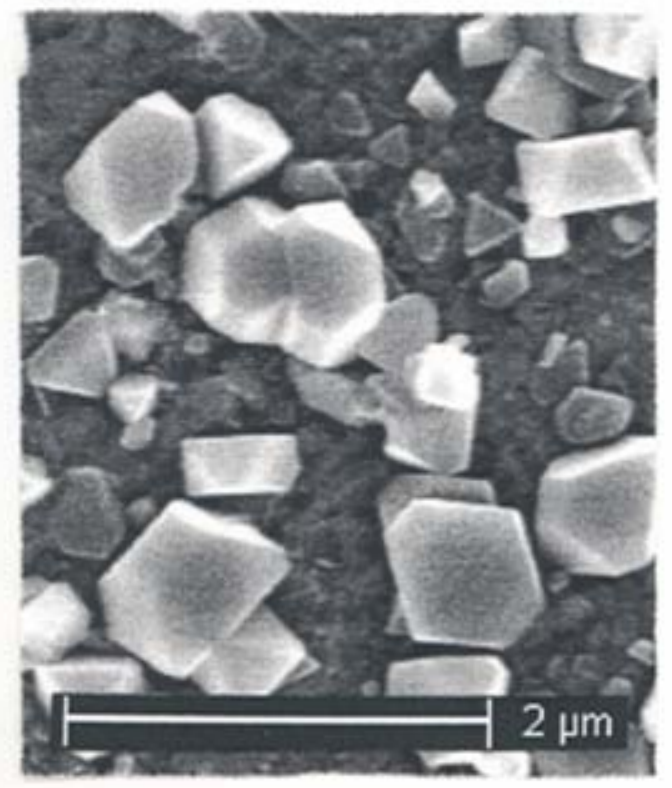

(b)

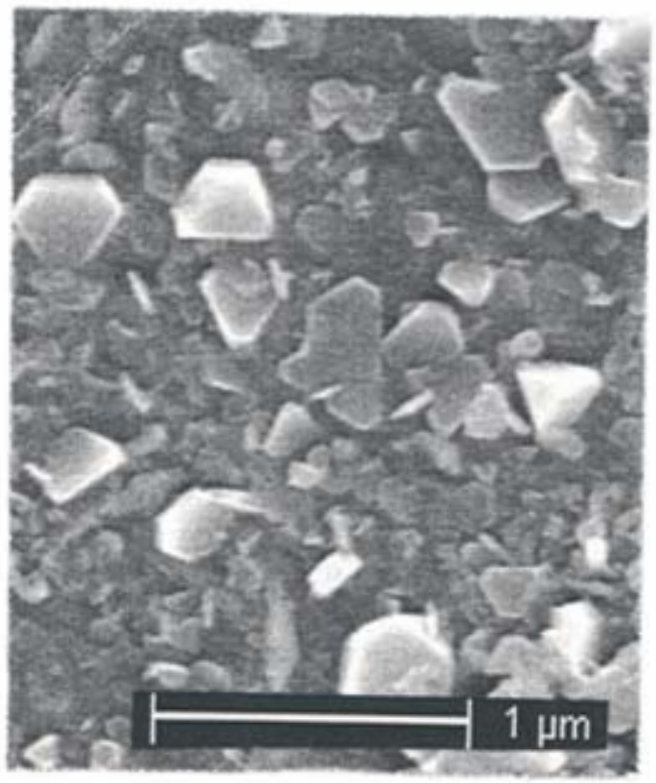

(d)

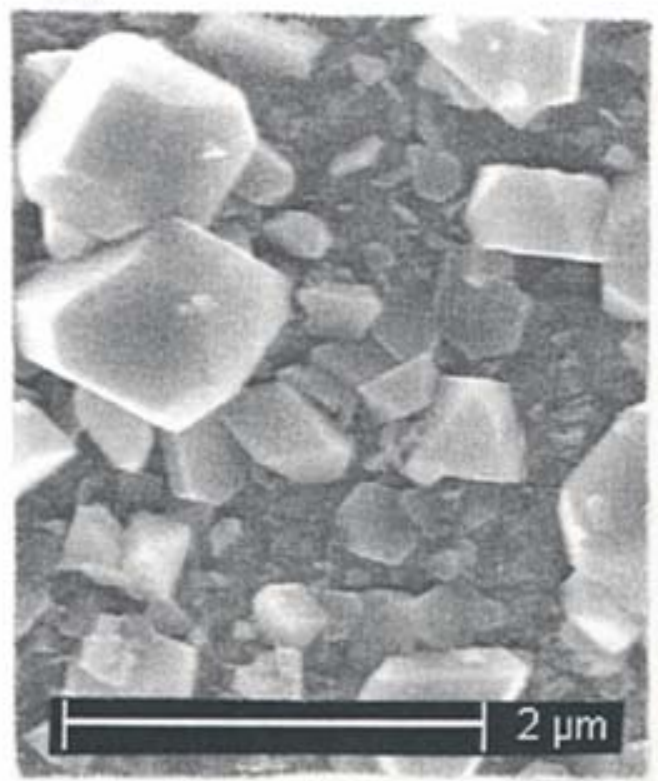

Fig. 1. High magnification SEM photographs of Alloy 600 after exposure to hydrogenated water at $260^{\circ} \mathrm{C}$ : (a) $1000 \mathrm{hr}$, (b) $2000 \mathrm{hr}$, (c) $5000 \mathrm{hr}$, (d) $10,000 \mathrm{hr}$. 
(a)

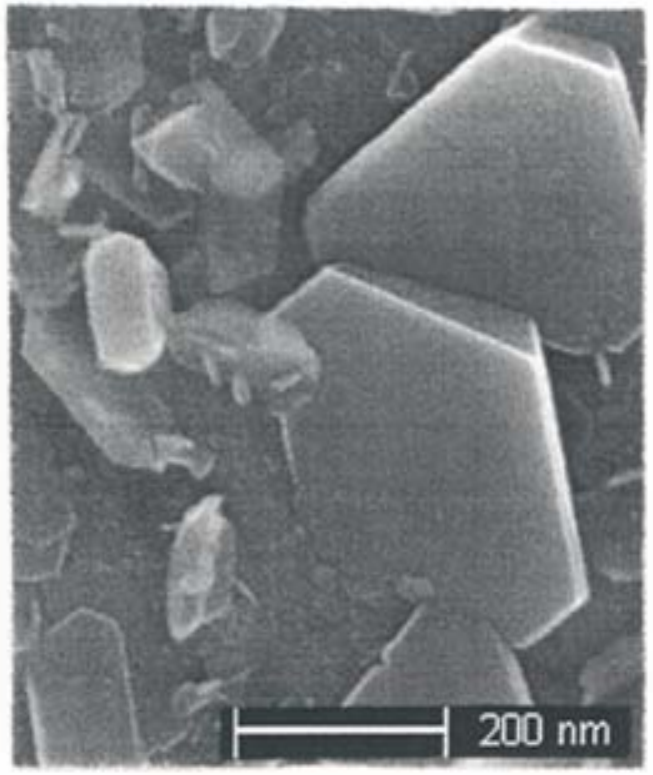

(b)

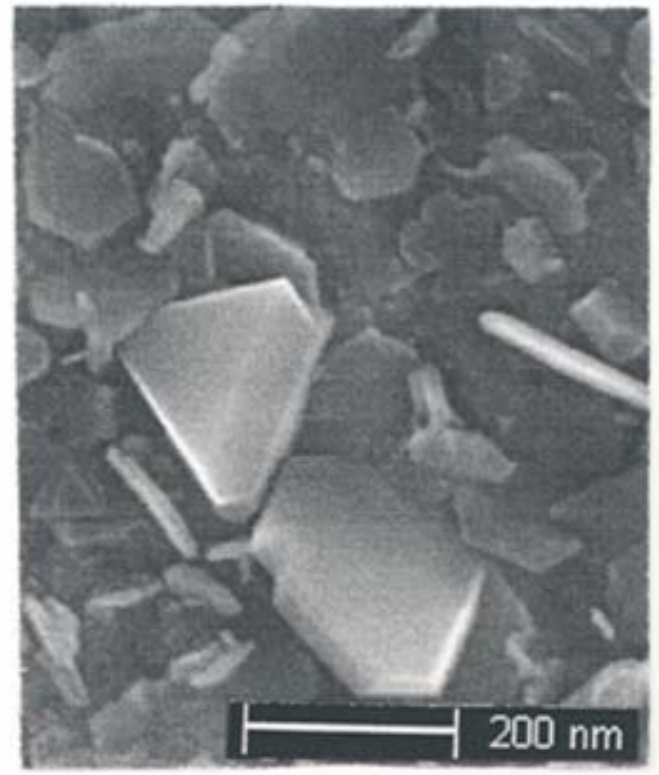

Fig. 2. High magnification SEM photographs of outer corrosion oxide crystals showing growth of hexagonal platelets into polyhedra: (a) $1000 \mathrm{hr}$., (b) $8000 \mathrm{hr}$. 


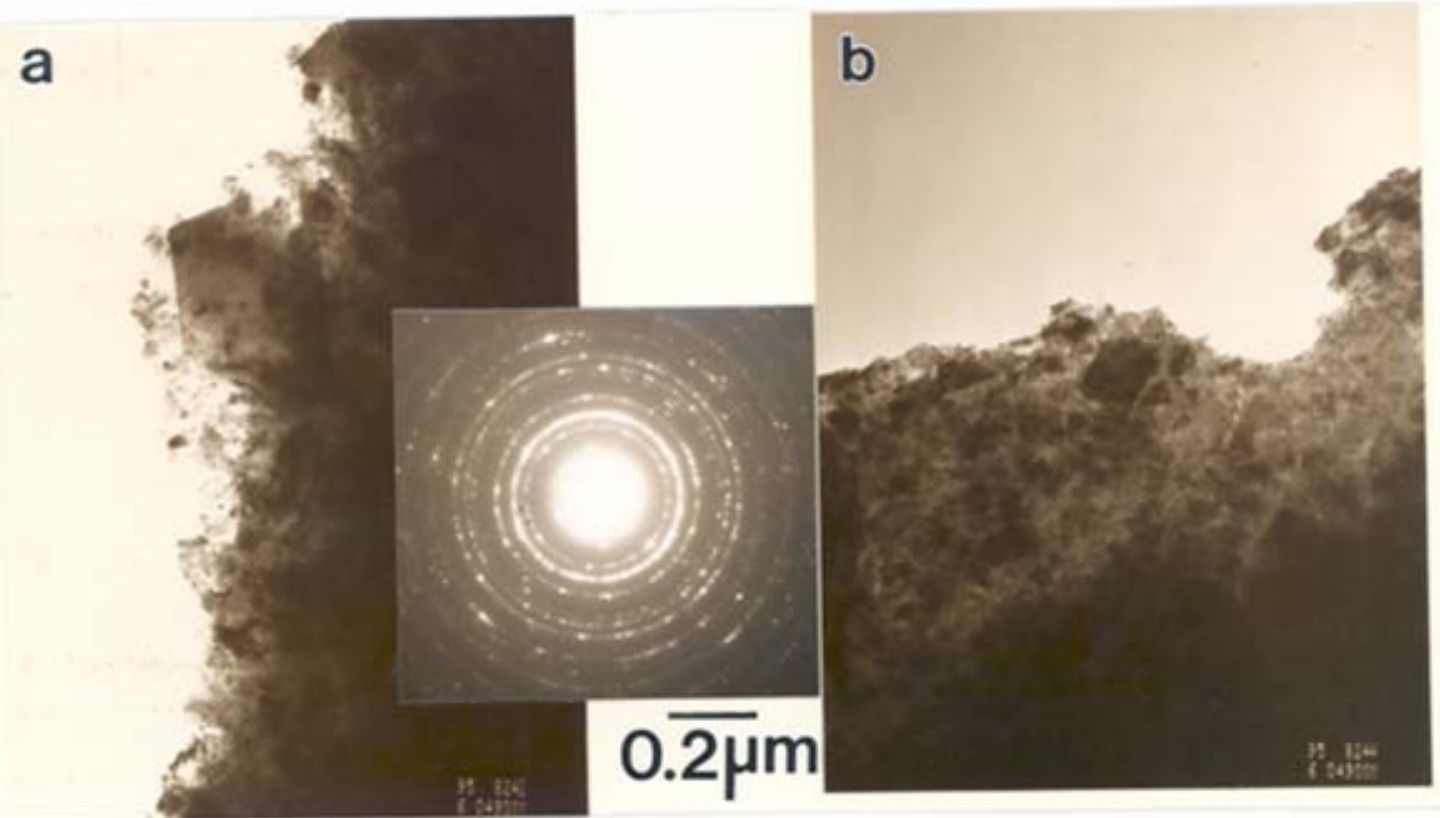

Fig. 3. Bright field TEM photographs taken through Alloy 600 corrosion film on 10,000 $\mathrm{hr}$ specimen (I67), including electron diffraction pattern. 

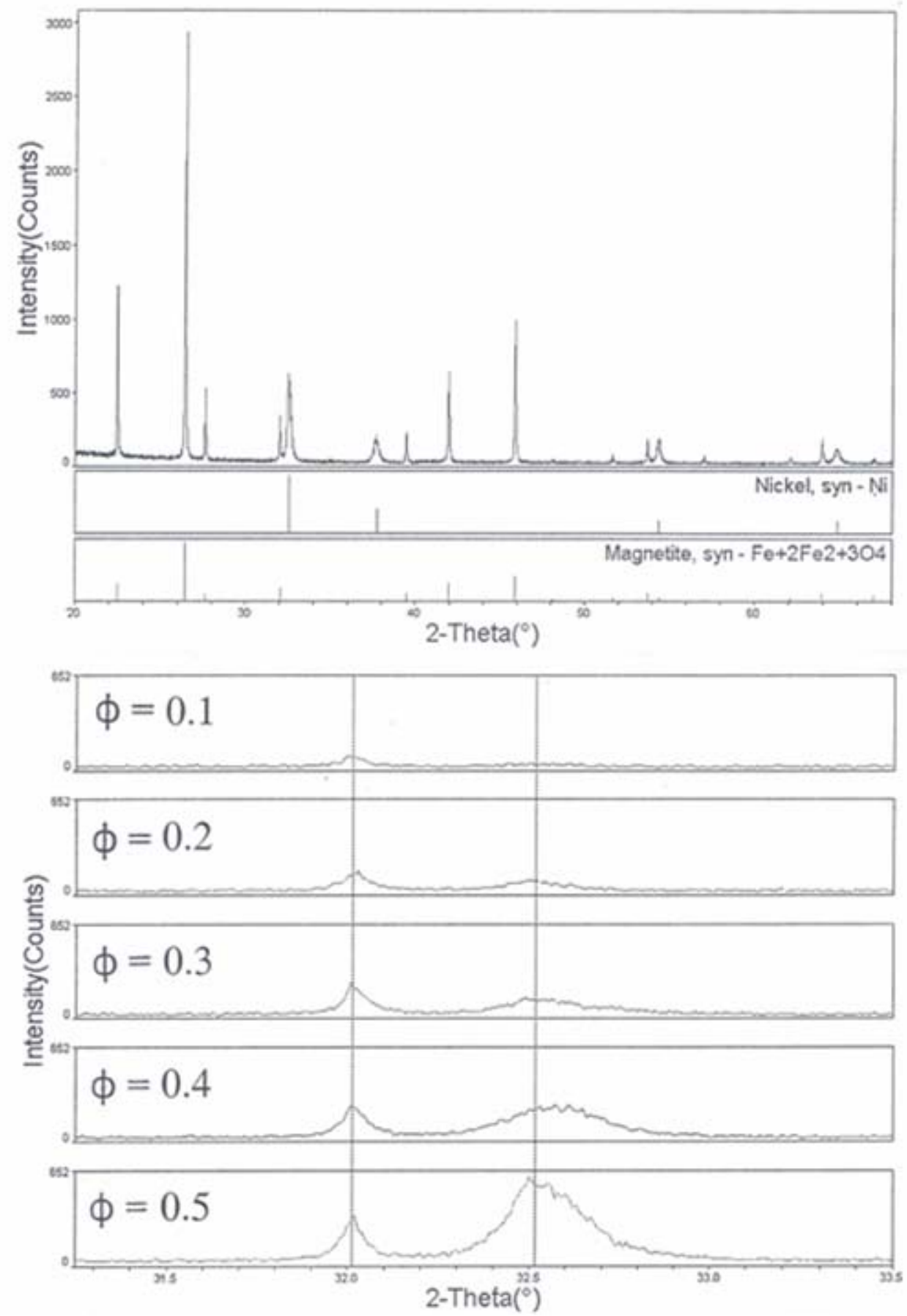

Fig. 4. Grazing incidence XRD pattern for 10,000 hr corrosion specimen (AX05): (a) full scan at $\phi=0.5^{\circ}$ and (b) expanded $2 \theta$ region in vicinity of Alloy 600 nickel [111] peak at incidence angles $\phi=0.1,0.2,0.3,0.4$ and $0.5^{\circ}$. Spinel [400] peak is also shown at $22=32.0^{\circ}$. 


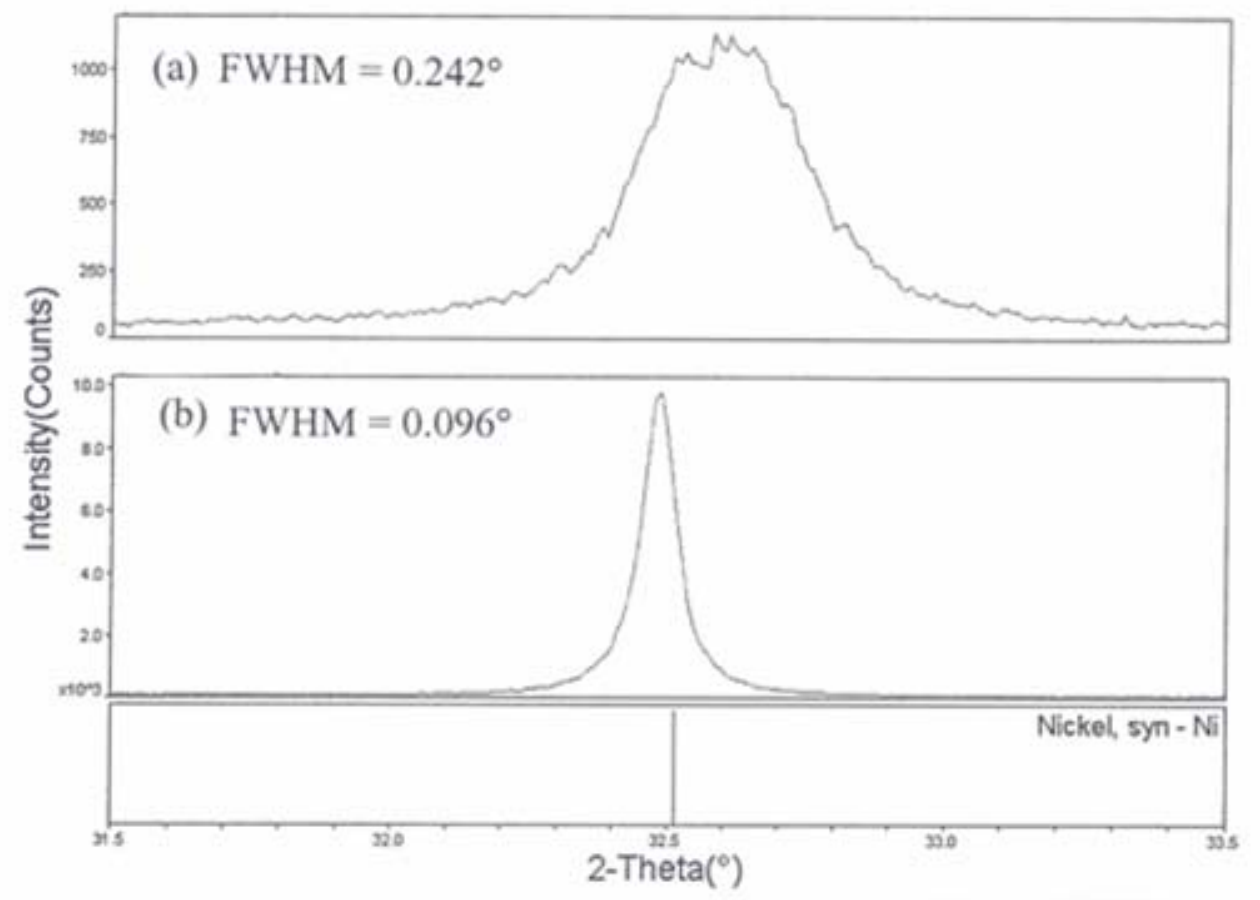

Fig. 5. Effect of angle of grazing incidence on FWHM of [111] Alloy 600 XRD peak: (a) $\phi=0.5^{\circ}$ and (b) $\phi=16^{\circ}$. (Results for as-polished, unexposed specimen.) 

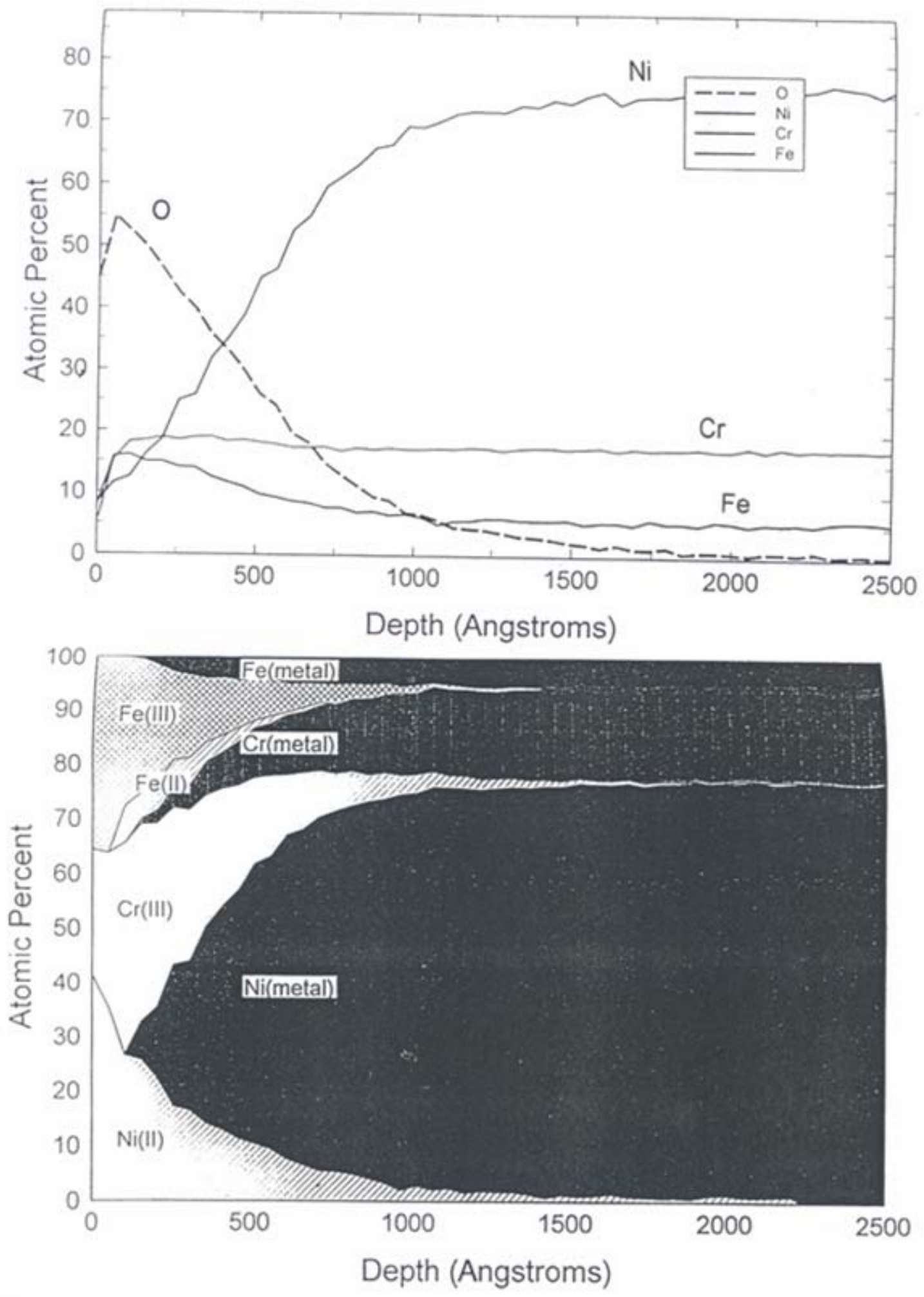

Fig. 6 Elemental (upper) and speciated (lower) composition profiles of Alloy 600 corrosion layer after $5000 \mathrm{hrs}$ (I75). 

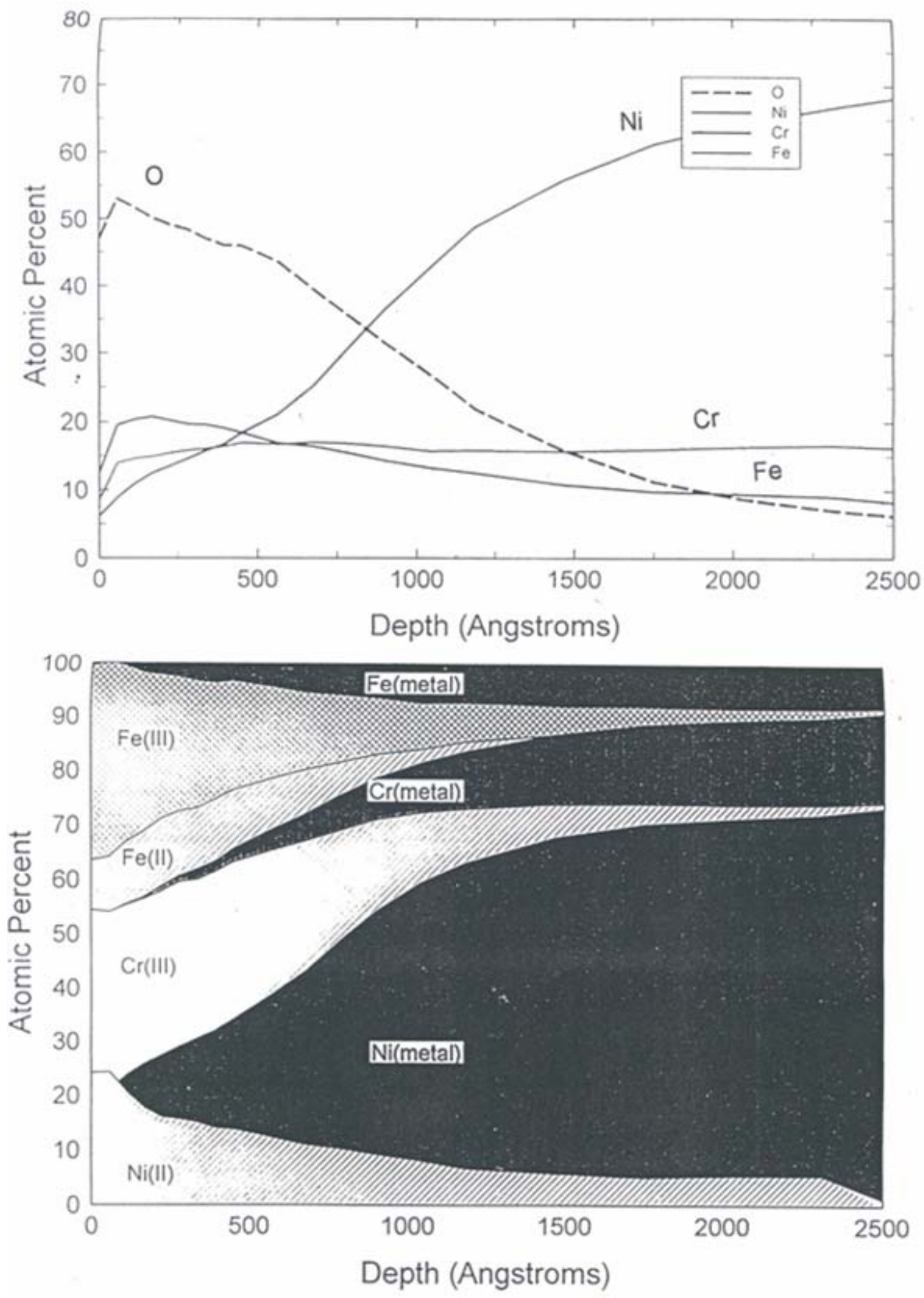

Fig. 7. Elemental (upper) and speciated (lower) composition profiles of Alloy 600 corrosion layer after 10,000 hrs (I67). 


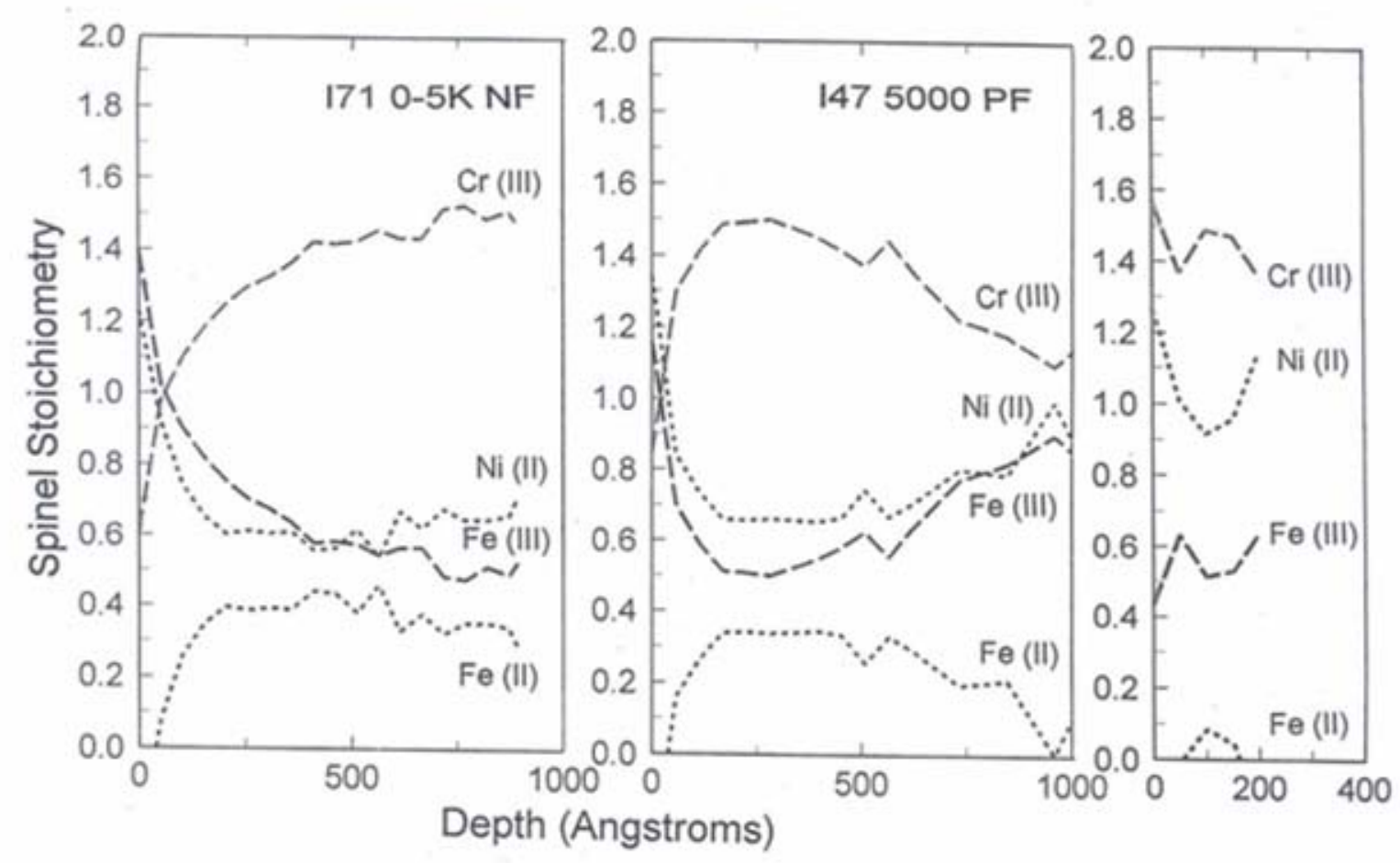

Fig. 8. Indicated stoichiometry of corrosion oxide spinel $\left(\mathrm{Ni}_{\mathrm{y}} \mathrm{Fe}_{1-\mathrm{y}}\right)\left(\mathrm{Fe}_{2-\mathrm{x}} \mathrm{Cr}_{\mathrm{x}}\right) \mathrm{O}_{4}$ versus sputter depth. (a) Inner layer $\mathrm{Cr}(\mathrm{III})=1.45$ (no interference from ferrite-rich crystals). (b) Interference from outer layer crystals creates an apparent $\mathrm{Cr}$ (III) depletion beyond 300 D. (c) Reanalysis of I47 after removal of outer layer crystals. 


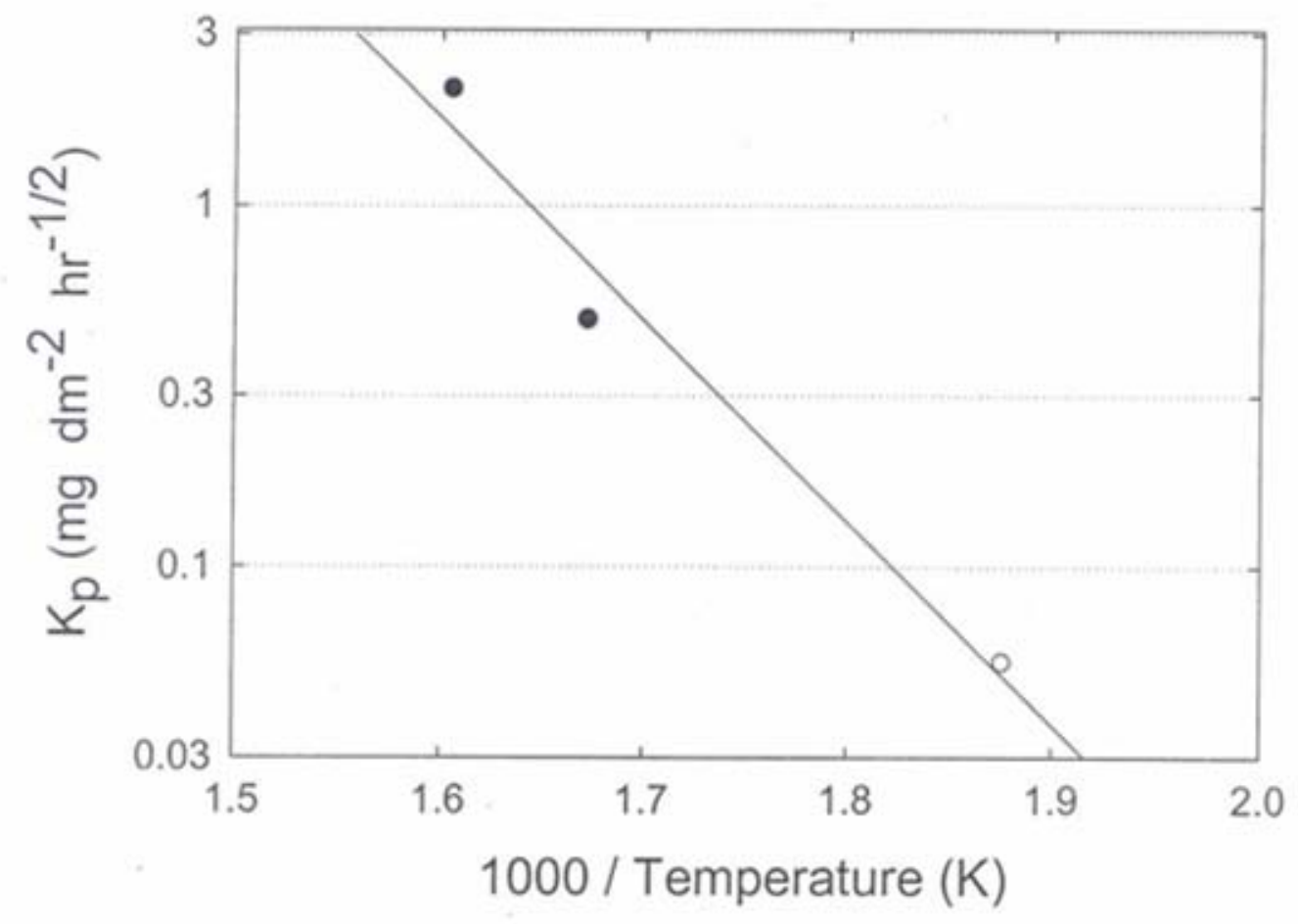

Fig. 9. Effect of temperature on corrosion rate of Alloy 600 in hydrogenated water: C [19]. 